\title{
Plant Preference for Ammonium versus Nitrate: A Neglected Determinant of Ecosystem Functioning?
}

\author{
S. Boudsocq, ${ }^{1, \star}$ A. Niboyet, ${ }^{2}$ J. C. Lata, ${ }^{3}$ X. Raynaud, ${ }^{3}$ N. Loeuille, ${ }^{4}$ J. Mathieu, ${ }^{3}$ M. Blouin, ${ }^{5}$ \\ L. Abbadie, ${ }^{3}$ and S. Barot ${ }^{6}$
}

1. Biogéochimie et Écologie des Milieux Continentaux (BioEMCo), Unité Mixte de Recherche (UMR) 7618, CNRS, Ecole Normale Supérieure (ENS), 46 Rue d'Ulm, 75230 Paris Cedex 05, France; and Écologie Fonctionnelle et Biogéochimie des Sols et des AgroÉcosystèmes, UMR 1222, Institut National de la Recherche Agronomique (INRA), Place Pierre Viala, 34060 Montpellier Cedex 01, France; 2. BioEMCo, UMR 7618, AgroParisTech, 78850 Thiverval Grignon, France; 3. BioEMCo, UMR 7618, Université Pierre et Marie Curie (UPMC), ENS, 46 Rue d’Ulm, 75230 Paris Cedex 05, France; 4. Laboratoire Écologie-Évolution, UMR 7625, UPMC, 4 Place Jussieu, 75005 Paris, France; and Écologie des Populations et Communautés, UMR 2031, INRA, 75005 Paris, France; 5. BioEMCo, UMR 7618, Universités Paris-Est Créteil Val de Marne, 61 avenue du Général De Gaulle, 94010 Créteil, France; 6. BioEMCo, UMR 7618, Institut de Recherche pour le Développement, ENS, 46 Rue d’Ulm, 75230 Paris Cedex 05, France

Submitted July 7, 2011; Accepted March 14, 2012; Electronically published May 24, 2012

Online enhancements: appendixes.

A BST RACT: Although nitrogen $(\mathrm{N})$ availability is a major determinant of ecosystem properties, little is known about the ecological importance of plants' preference for ammonium versus nitrate $(\beta)$ for ecosystem functioning and the structure of communities. We modeled this preference for two contrasting ecosystems and showed that $\beta$ significantly affects ecosystem properties such as biomass, productivity, and $\mathrm{N}$ losses. A particular intermediate value of $\beta$ maximizes the primary productivity and minimizes mineral $\mathrm{N}$ losses. In addition, contrasting $\beta$ values between two plant types allow their coexistence, and the ability of one type to control nitrification modifies the patterns of coexistence with the other. We also show that species replacement dynamics do not lead to the minimization of the total mineral $\mathrm{N}$ pool nor the maximization of plant productivity, and consequently do not respect Tilman's $R^{*}$ rule. Our results strongly suggest in the two contrasted ecosystems that $\beta$ has important consequences for ecosystem functioning and plant community structure.

Keywords: ammonium, biological invasion, coexistence, nitrate, nitrification, resource partitioning.

\section{Introduction}

Nitrogen (N) is generally considered as the main factor limiting plant growth in many temperate terrestrial ecosystems (Vitousek and Howarth 1991). Most studies on ecosystem function have considered $\mathrm{N}$ as a single resource despite the fact that plants are able to assimilate different forms of $\mathrm{N}$, such as ammonium $\left(\mathrm{NH}_{4}^{+}\right)$, nitrate $\left(\mathrm{NO}_{3}^{-}\right)$,

\footnotetext{
* Corresponding author; e-mail: boudsocq@supagro.inra.fr.
}

Am. Nat. 2012. Vol. 180, pp. 60-69. (c) 2012 by The University of Chicago. 0003-0147/2012/18001-53156\$15.00. All rights reserved. DOI: $10.1086 / 665997$ and organic N (Begon et al. 1998; Marschner 2008). The implications of plant organic $\mathrm{N}$ nutrition (Hodge et al. 2001; Weigelt et al. 2005) and symbiotic $\mathrm{N}$ fixation (Vitousek et al. 2002; Menge et al. 2008) for ecosystem function and plant communities have received considerable attention (Schimel and Bennett 2004). In contrast, few studies have examined the consequences of plant preference for $\mathrm{NH}_{4}^{+}$versus $\mathrm{NO}_{3}^{-}$on ecosystems' functioning, that is, at ecosystem scale, though this preference is well documented from the physiological point of view (Williams and Miller 2001; Marschner 2008) and the processes controlling the availability of $\mathrm{NH}_{4}^{+}$and $\mathrm{NO}_{3}^{-}$in soils are widely studied (Frank and Groffman 2009). More precisely, most studies focusing on the ecological consequences of plant preference for different $\mathrm{N}$ forms do not distinguish explicitly $\mathrm{NH}_{4}^{+}$from $\mathrm{NO}_{3}^{-}$but rather consider "inorganic $\mathrm{N}$ " versus "organic N" (Harrison et al. 2007; Kahmen et al. 2008).

From an energetic point of view, $\mathrm{NH}_{4}^{+}$uptake and assimilation are less costly than $\mathrm{NO}_{3}^{-}$uptake and assimilation (Salsac et al. 1987). This could constitute an advantage for plants being very competitive for $\mathrm{NH}_{4}^{+}$absorption. However, some studies show that $\mathrm{NH}_{4}^{+}$, when it is the only $\mathrm{N}$ source for plants, can cause severe toxicity symptoms (de Graaf et al. 1998; Britto et al. 2001). This $\mathrm{NH}_{4}^{+}$toxicity could counterbalance the energetic advantage in taking up $\mathrm{NH}_{4}^{+}$rather than $\mathrm{NO}_{3}^{-}$. Moreover, since plants may also exhibit large demands in $\mathrm{K}^{+}, \mathrm{Ca}^{2+}$, and other cations, the absorption of $\mathrm{NO}_{3}^{-}$can lead to a more even charge balance for plants than the absorption of $\mathrm{NH}_{4}^{+} . \mathrm{NO}_{3}^{-}$is also easier to store in plant tissues than $\mathrm{NH}_{4}^{+}$. Furthermore, due to its electronic charge, $\mathrm{NH}_{4}^{+}$is often adsorbed to organo- 
mineral complexes (Brady and Weil 2001; Marschner 2008) and thus can be retained in the soil. Conversely, the negative charge of $\mathrm{NO}_{3}^{-}$makes this form of $\mathrm{N}$ much more mobile and thus more prone to loss and thereby less available for plants (Brady and Weil 2001; Marschner 2008). On the other hand, this higher mobility leads to a more rapid diffusion to roots and thus to an easier access for plants to the $\mathrm{NO}_{3}^{-}$that is not lost than to the $\mathrm{NH}_{4}^{+}$that is not lost. These physiological costs and physical limitations constrain plant strategy in opposite directions and might thus impose a trade-off between the absorption of the two $\mathrm{N}$ forms as suggested by Maire et al. (2009).

Some plants are able to inhibit (Lata et al. 1999, 2000, 2004; Subbarao et al. 2007a, 2007b) or stimulate (Lata et al. 2000; Hawkes et al. 2005) nitrification, that is, the microbially mediated conversion of $\mathrm{NH}_{4}^{+}$into $\mathrm{NO}_{3}^{-}$, thereby altering the relative amount of $\mathrm{NH}_{4}^{+}$and $\mathrm{NO}_{3}^{-}$available in the soil for their own mineral $\mathrm{N}$ nutrition, as well as for the mineral $\mathrm{N}$ nutrition of their competitors. This should have large ecological consequences, and a recent model assessing the impact of nitrification inhibition by plants on ecosystem functioning (Boudsocq et al. 2009) has reported that such an inhibition of nitrification may increase primary productivity and ecosystem fertility in a sustainable way. Indeed, inhibiting nitrification enhances the conservation of mineral $\mathrm{N}$ in the soil, as $\mathrm{NO}_{3}^{-}$is more prone than $\mathrm{NH}_{4}^{+}$to being lost from the ecosystem as explained above. This could be of particular importance in highly constrained ecosystems with poor and/or welldrained soil. It has also been hypothesized that nitrification-inhibiting plants may also have developed a greater capacity for the absorption of $\mathrm{NH}_{4}^{+}$than for $\mathrm{NO}_{3}^{-}$, and that the propensity of a species to take up either $\mathrm{NH}_{4}^{+}$or $\mathrm{NO}_{3}^{-}$could influence the recycling efficiency and thereby the productivity of the whole ecosystem (Barot et al. 2007; Boudsocq et al. 2009).

Furthermore, recent work supports the hypothesis that $\mathrm{N}$ preference may influence plant community structure through changes in competition for $\mathrm{N}$ between species (Aanderud and Bledsoe 2009). Indeed, though some species may possess an important plasticity in their absorption of different $\mathrm{N}$ forms (Houlton et al. 2007), others show a preference for a particular form, and the relative abundance of different $\mathrm{N}$ forms in the soil-due to microbial $\mathrm{N}$ transformations in the soil but also to the different forms of atmospheric N inputs (Holland et al. 1999; Galloway et al. 2004)_could affect the coexistence between plant species (Tilman 1985). Indeed, the concepts of resource partitioning and niche complementarity support the idea that species that differ in their resource use are more likely to coexist (Pacala and Tilman 1994; Holt et al. 2008). Ashton et al. (2010) published a study suggesting that these concepts should apply concerning $\mathrm{NH}_{4}^{+}$and $\mathrm{NO}_{3}^{-}$uptake and assimilation. Similarly, controlling nitrification rates could play a key role in the dynamics of plant communities as stimulation and inhibition of this process have been shown to strongly affect plant invasions (Lata et al. 2004; Hawkes et al. 2005; Rossiter-Rachor et al. 2009). Taken together, plant influence on nitrification and preference for $\mathrm{NH}_{4}^{+}$versus $\mathrm{NO}_{3}^{-}$should interact to determine the availability of mineral $\mathrm{N}$ and plant competitiveness.

Using a modified version of the mathematical model from Boudsocq et al. (2009) the aim of our study is to assess the importance of plants' relative ability to take up $\mathrm{NH}_{4}^{+}$and $\mathrm{NO}_{3}^{-}$for ecosystem functioning and plant community structure. More precisely, our objectives are to address these questions: (i) How does the preference of plants for $\mathrm{NH}_{4}^{+}$versus $\mathrm{NO}_{3}^{-}$influence primary productivity, plant biomass, and soil mineral $\mathrm{N}$ stocks? (ii) Can plant productivity and biomass be maximized for a particular value of plant preference for $\mathrm{NH}_{4}^{+}$versus $\mathrm{NO}_{3}^{-}$, and if that is the case, what are the ecological mechanisms leading to this maximization? (iii) Can plant types that differ only in their preference for $\mathrm{NH}_{4}^{+}$versus $\mathrm{NO}_{3}^{-}$coexist? (iv) Finally, how is the ability of a plant to become invasive or make a system resistant to invasion affected by its preference for $\mathrm{NH}_{4}^{+}$versus $\mathrm{NO}_{3}^{-}$, and its ability to control nitrification?

The model is parameterized for two contrasting natural ecosystems whose $\mathrm{N}$ cycles are well described in the literature: the Pawnee site (Colorado; Woodmansee et al. 1978), a temperate short-grass prairie, and the Lamto site (Ivory Coast), a tropical humid savanna (Abbadie et al. 2006; Boudsocq et al. 2009).

\section{Model and Simulation Approach}

Our model (fig. 1) describes the dynamics of $\mathrm{N}$ between different compartments: dead organic matter $(D), \mathrm{NH}_{4}^{+}$ $\left(N_{\mathrm{A}}\right), \mathrm{NO}_{3}^{-}\left(N_{\mathrm{N}}\right)$ and one or two plant types $\left(P_{1}\right.$ and $\left.P_{2}\right)$. The model is described by the following set of differential equations:

$$
\begin{aligned}
\frac{d P_{i}}{d t}= & \beta_{i} u N_{\mathrm{A}} P_{i}+\left(1-\beta_{i}\right) u N_{\mathrm{N}} P_{i}-\left(d+l_{P}-f\right) P_{i} \\
\frac{d D}{d t}= & R_{D}+d \sum_{i} P_{i}-\left(m+l_{D}\right) D \\
\frac{d N_{\mathrm{A}}}{d t}= & R_{\mathrm{A}}+m D-\sum_{i}\left(\beta_{i} P_{i}\right) u N_{\mathrm{A}} \\
& -\left(l_{N_{\mathrm{A}}}+n e^{-\Sigma i_{i} P_{i}}\right) N_{\mathrm{A}}
\end{aligned}
$$




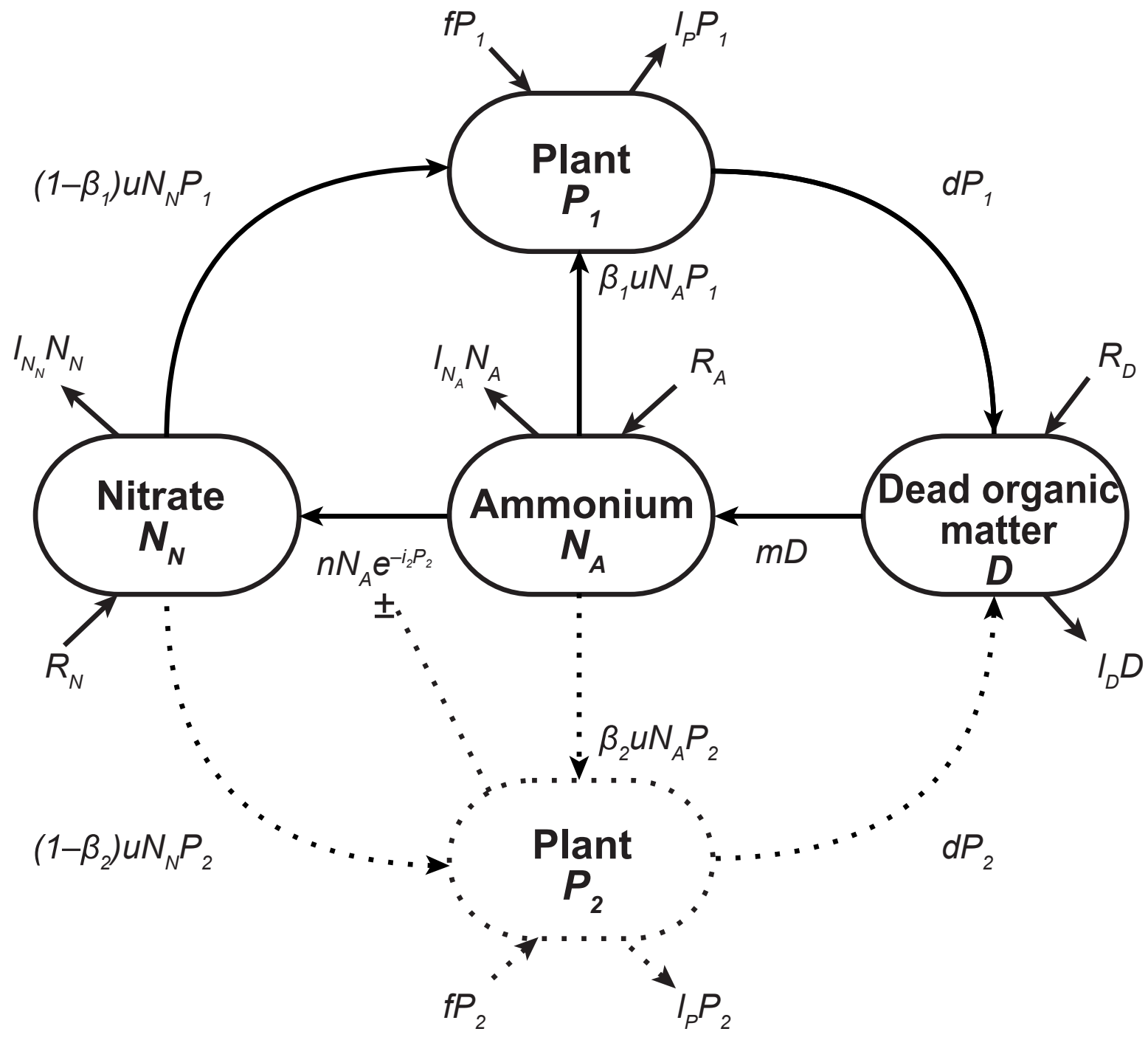

Figure 1: General model of $\mathrm{N}$ cycling in a terrestrial ecosystem. The labels associated with each arrow indicate the formula used for the corresponding flux. The dotted boxes and arrows are taken into account for testing coexistence and invasion situations only. Definitions of parameters can be found in table 1 .

$\frac{d N_{\mathrm{N}}}{d t}=R_{\mathrm{N}}+n N_{\mathrm{A}} e^{-\Sigma i_{i} P_{i}}-\left[\sum_{i}\left(1-\beta_{i}\right) u P_{i}+l_{N_{\mathrm{N}}}\right] N_{\mathrm{N}}$.

The primary productivity $(\Phi)$ equation is

$$
\frac{d \phi}{d t}=\sum_{i}\left(\beta_{i} u P_{i}\right) N_{\mathrm{A}}+\sum_{i}\left[\left(1-\beta_{i}\right) u P_{i}\right] N_{\mathrm{N}}+f \sum_{i}\left(P_{i}\right) .
$$

Model parameters and definitions are given in table 1.

Plants build up their biomass by absorbing $\mathrm{N}$ from the two mineral $\mathrm{N}$ pools, that is, $\mathrm{NH}_{4}^{+}$and $\mathrm{NO}_{3}^{-}$, with the rates of $\beta_{i} u$ and $\left(1-\beta_{i}\right) u$, respectively. Term $\beta_{i}$ represents the preference of the plant $i$ for $\mathrm{NH}_{4}^{+}$, and $\left(1-\beta_{i}\right)$ is the preference of the plant $i$ for $\mathrm{NO}_{3}^{-}\left(\beta_{i}\right.$ ranges between 0 and 1$)$, while $u$ represents the $\mathrm{N}$ uptake capacity of plants. Note that to stay focused on plant preference for $\mathrm{NH}_{4}^{+}$versus $\mathrm{NO}_{3}^{-}$, the model does not allow plants to take up organic $\mathrm{N}$, which is assumed to be negligible in the studied ecosystems (Schimel and Bennett 2004). Plants' uptakes of $\mathrm{N}$ are modeled using "donor-recipient" functions, that is, the fluxes are proportional to the sizes of the mineral $\mathrm{N}$ stocks and the plant compartments. Note that another formalism, such as Monod equations for the absorption of $\mathrm{N}$, would have been more realistic (donor-recipient functions do not saturate), but in this article, Monod equations do not affect qualitatively the results and make the model much more complex. In turn, plant mortality leads to a flux of $\mathrm{N}$ from 
Table 1: Parameters of the Pawnee site

\begin{tabular}{|c|c|c|c|}
\hline Parameter & Dimension & Definition & Value \\
\hline$f$ & $\mathrm{yr}^{-1}$ & Symbiotic $\mathrm{N}$ fixation rate & .01 \\
\hline$d$ & $\mathrm{yr}^{-1}$ & Plant recycling rate & .258 \\
\hline$l_{P}$ & $\mathrm{yr}^{-1}$ & Plant loss rate & 0 \\
\hline$R_{D}$ & $\mathrm{~kg} \mathrm{~N} \mathrm{ha}^{-1} \mathrm{yr}^{-1}$ & Annual organic $\mathrm{N}$ input rate & 0 \\
\hline$m$ & $\mathrm{yr}^{-1}$ & DOM recycling rate & .00654 \\
\hline$l_{D}$ & $\mathrm{yr}^{-1}$ & DOM loss rate & .00138 \\
\hline$R_{\mathrm{A}}$ & $\mathrm{kg} \mathrm{N} \mathrm{ha}^{-1} \mathrm{yr}^{-1}$ & Annual $\mathrm{NH}_{4}^{+}$input & 3 \\
\hline$u$ & ha $\mathrm{kg} \mathrm{N}^{-1} \mathrm{yr}^{-1}$ & $\mathrm{~N}$ uptake rate & .01336 \\
\hline$n$ & $\mathrm{yr}^{-1}$ & Nitrification rate & .05 \\
\hline$l_{\mathrm{NA}}$ & $\mathrm{yr}^{-1}$ & $\mathrm{NH}_{4}^{+}$loss rate & .05 \\
\hline$R_{\mathrm{N}}$ & $\mathrm{kg} \mathrm{N} \mathrm{ha}^{-1} \mathrm{yr}^{-1}$ & Annual $\mathrm{NO}_{3}^{-}$input & 3 \\
\hline$l_{\mathrm{NN}}$ & $\mathrm{yr}^{-1}$ & $\mathrm{NO}_{3}^{-}$loss rate & .15 \\
\hline$\beta$ & Dimensionless & Affinity for $\mathrm{NH}_{4}^{+}$versus $\mathrm{NO}_{3}^{-}$ & NA \\
\hline$i$ & ha $\mathrm{kg} \mathrm{N}^{-1}$ & Nitrification inhibition/stimulation rate & \pm .02 \\
\hline
\end{tabular}

Note: $\mathrm{DOM}=$ dissolved organic matter.

the $P$ to the $D$ compartment at a rate $d$. This dead organic matter ( $D$; including litter and dead root biomass) is mineralized, leading to a flux of $\mathrm{N}$ to the $N_{\mathrm{A}}$ compartment, with a rate $m . \mathrm{NH}_{4}^{+}$is then absorbed by plants, or transformed into $\mathrm{NO}_{3}^{-}$(i.e., nitrified) at a rate $n$. Plant type $P_{2}$ is assumed to be able to control the rate of nitrification, either inhibiting (Lata et al. 1999, 2000, 2004; Subbarao et al. 2007a, 2007b) or stimulating (Lata et al. 2000; Hawkes et al. 2005) by a coefficient $i$, so that the flux of nitrification is modeled as $n N_{A} e^{-\Sigma i_{i} P_{i}}(i>0$ when plants inhibit nitrification and $i<0$ when plants stimulate nitrification). Finally, $\mathrm{NO}_{3}^{-}$is absorbed by plants.

In natural ecosystems, losses occur from these four compartments. Fire can cause significant losses from the $P$ and $D$ compartments (Bowman et al. 2009). Erosion and leaching can also lead to losses from the $D$ compartment (Marschner and Rengel 2007). $\mathrm{NH}_{4}^{+}$can be lost through volatilization, making it unavailable for plants. Finally, $\mathrm{NH}_{4}^{+}$and $\mathrm{NO}_{3}^{-}$can be lost through leaching, and $\mathrm{NO}_{3}^{-}$ can also be lost through denitrification (Marschner and Rengel 2007). These losses are included in our model with the rates of $l_{P}, l_{D}, l_{\mathrm{NA}}$, and $l_{\mathrm{NN}}$ for losses from the $P, D, N_{\mathrm{A}}$, and $N_{\mathrm{N}}$ compartments, respectively.

There are two main sources of $\mathrm{N}$ inputs to the ecosystem: atmospheric $\mathrm{N}$ deposition, and the biotic fixation of atmospheric $\mathrm{N}_{2}$ by symbiotic and nonsymbiotic microorganisms (Galloway et al. 2004). Mineral atmospheric $\mathrm{N}$ deposition provides constant $\mathrm{N}$ inputs to the $N_{\mathrm{A}}$ and $N_{\mathrm{N}}$ compartments ( $R_{\mathrm{A}}$ and $R_{\mathrm{N}}$, respectively). Organic $\mathrm{N}$ deposition and $\mathrm{N}$ nonsymbiotic fixation are modeled by a constant $\mathrm{N}$ input to the $D$ compartment of $R_{D}$. Finally, the symbiotic $\mathrm{N}$ fixation of $\mathrm{N}_{2}$ provides an $\mathrm{N}$ input to the $P$ compartment proportional to a constant rate $f$ and to the size of the $P$ compartment. Stocks are expressed in kilograms of $\mathrm{N}$ per hectare and fluxes in kilograms of $\mathrm{N}$ per hectare per year.

In order to study the effect of $\beta_{i}$ (preference for $\mathrm{NH}_{4}^{+}$) on ecosystem properties, we determine the mathematical equations corresponding to the compartments' steady states by setting the system of differential equations to 0 and define the model equilibrium conditions (appendix A, available online). First considering only one plant type $\left(P_{1}\right)$, we then determine by numerical simulations the value of $\beta_{1}$ leading to the highest biomass and plant productivity for a given set of parameters (noted $\beta_{\text {opt1 }}$ ) and analyze the sensitivity of $\beta_{\mathrm{opt1}}$ to ecosystem parameters including nitrification rates, $\mathrm{NO}_{3}^{-}$loss rates, and $\mathrm{NH}_{4}^{+}$and $\mathrm{NO}_{3}^{-}$deposition rates (app. B, available online). To do so, we use Mathematica, version 8.0, to find the value of $\beta$ for which each equilibrium compartment derivative with respect to $\beta$ is null (command: Solve [D (<compartment, $\beta>)=0$ ] ). Then, in order to study the ecological importance of plant $\mathrm{NH}_{4}^{+}$versus $\mathrm{NO}_{3}^{-}$uptake and its impact on plant invasion, we add a second plant compartment that differs from the first one by its preference for $\mathrm{NH}_{4}^{+}$ and $\mathrm{NO}_{3}^{-}$(fig. 1) and by its ability to control nitrification. We thus distinguish two plant compartments $\left(P_{1}\right.$ and $\left.P_{2}\right)$ having two distinct preferences for $\mathrm{NH}_{4}^{+}$versus $\mathrm{NO}_{3}^{-}\left(\beta_{1}\right.$ and $\beta_{2}$, respectively). We then perform simulations with one plant type being the "resident" species (i.e., its starting biomass is $100 \mathrm{~kg} \mathrm{~N} \mathrm{ha}^{-1}$, which is close to the plant biomass observed in the Pawnee and Lamto sites; Woodmansee et al. 1978; Abbadie et al. 2006) and the other one being the "invader" type (i.e., its starting biomass is 0.01 $\mathrm{kg} \mathrm{N} \mathrm{ha}{ }^{-1}, 10,000$-fold lower than the resident). The numerical simulations of the differential equations (eqq. [1][4]) have a time step of 1 year and are long enough to reach steady states $(10,000$ steps of time, as determined 
by preliminary simulations). Stable coexistence between plant types is checked using mutual invasibility (Chesson 2000), and the role of type (i.e., invader or resident) is switched for each tested pair of type. We first simulate the invasion of two plant types differing only by their preference for $\mathrm{NH}_{4}^{+}(\beta)$ and then consider the case where $P_{2}$ is able to inhibit or to stimulate nitrification. In these latter cases, $P_{1}$ and $P_{2}$ plants only differ by their preference for $\mathrm{NH}_{4}^{+}$and $\mathrm{NO}_{3}^{-}$and their ability to control nitrification. Except for $i$, the parameters used in the main text of this study come from the Woodmansee et al. article (1978)

\section{Results and Discussion}

Because our results are qualitatively similar for both ecosystems, we show only the results for the Pawnee site in the main text. Results for the Lamto site are given in the appendixes $\mathrm{B}-\mathrm{D}$, available online.

\section{Ecosystem Properties}

Plant biomass and primary productivity are maximized for a particular value of plant $\mathrm{NH}_{4}^{+}$preference $\left(\beta_{\text {opt }} \approx 0.65\right.$; fig. 2 ). Overall, variations in $\beta$ lead to 10 -fold variations in plant biomass and productivity (fig. $2 A$ ). This particular preference $\left(\beta_{\text {opt }}\right)$ also leads to a minimization of the total mineral $\mathrm{N}$ losses (fig. $2 B$ ). We prove analytically in appendix A that this pattern always holds: whatever the value of $\beta_{\mathrm{opt}}$, when $P^{*}$ is maximized, plant productivity is maximized and mineral $\mathrm{N}$ losses are minimized. Moreover, using derivatives of equilibrium values with $\beta$, we show a positive relationship between the variation of $P^{*}$ and the variation of $D^{*}$ and between the variation of $P^{*}$ and the variation of plant productivity as functions of $\beta$ (preference for $\mathrm{NH}_{4}^{+}$). Conversely, we show a negative relationship between the variations of plant biomass/productivity and the variation of total mineral $\mathrm{N}$ losses as functions of $\beta$.

Concerning the variations of mineral $\mathrm{N}$ compartments as functions of $\beta$ (see fig. $2 B$ ), the higher the preference for $\mathrm{NH}_{4}^{+}$, the lower the size of the $\mathrm{NH}_{4}^{+}$pool. Symmetrically, the higher the preference for $\mathrm{NO}_{3}^{-}$, the lower the size of the $\mathrm{NO}_{3}^{-}$pool. However, in the Pawnee site, there are two exceptions to this general pattern: (i) when $\beta$ (preference for $\mathrm{NH}_{4}^{+}$) ranges between 0 and 0.15 , the higher the preference for $\mathrm{NH}_{4}^{+}$, the higher the availability of $\mathrm{NH}_{4}^{+}$, and (ii) when $\beta$ ranges between 0 and 0.40 , the higher the preference for $\mathrm{NO}_{3}^{-}$, the higher the availability of $\mathrm{NO}_{3}^{-}$. We give in appendix $\mathrm{A}$ an analytical study of the variations of the model compartments as functions of $\beta$. We identify in this appendix the general conditions that lead to such a pattern.

We show analytically that in Pawnee, the increase of $\mathrm{NH}_{4}^{+}$pool with $\beta$ can be due to three complementary

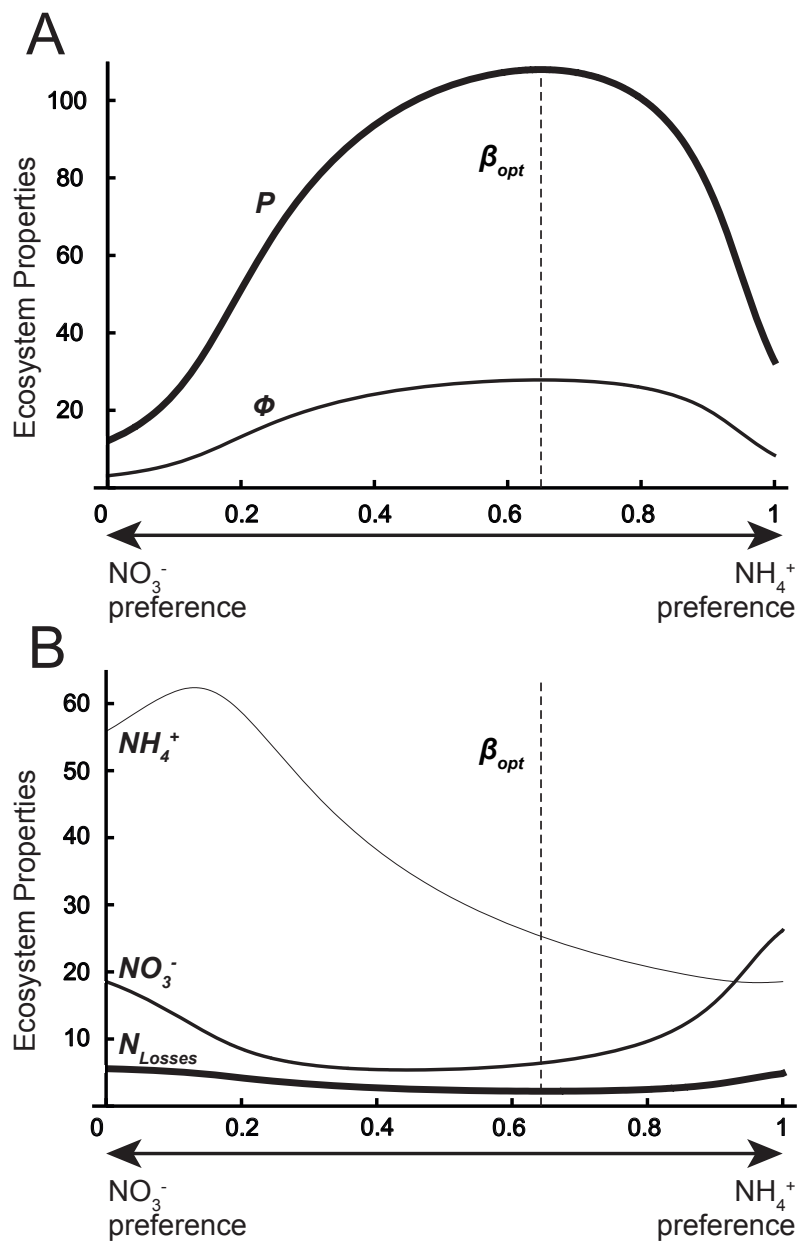

Figure 2: Variations in the size of ecosystem compartments $(P[A]$; $\mathrm{NH}_{4}^{+}$and $\mathrm{NO}_{3}^{-}[B]$ ) and fluxes (primary productivity $\phi[A]$ and $N_{\text {losses }}$ $[B])$ as a function of plant preference for $\mathrm{NH}_{4}^{+}$versus $\mathrm{NO}_{3}^{-}(\beta)$ for the Pawnee site. The sizes of the ecosystem compartments are expressed in kilograms of nitrogen per hectare, and the fluxes are expressed in kilograms of nitrogen per hectare per year. As shown in the figure, $\beta_{\mathrm{opt}}$ corresponds to the maximal plant biomass and primary productivity and to the minimum of $\mathrm{N}$ losses.

conditions (see eq. [A15.2] in app. A): (i) the low preference of plant for $\mathrm{NH}_{4}^{+}$(since $\beta$ ranges between 0 and 0.15 , see fig. $2 B$ ), (ii) the low plant biomass associated with low values of $\beta$, and (iii) the high recycling efficiency of dead plant biomass into $\mathrm{NH}_{4}^{+}$. These factors enable a significant amount of plant biomass that is transformed into $\mathrm{NH}_{4}^{+}$and that is not absorbed in high quantities by plants. So, $\mathrm{NH}_{4}^{+}$accumulates in the ecosystem as long as plants have their biomass increasing with $\beta$ while being specialized in $\mathrm{NO}_{3}^{-}$absorption $(0<\beta<0.15)$. Concerning $\mathrm{NO}_{3}^{-}$, when plants are specialized in $\mathrm{NO}_{3}^{-}$absorption $(\beta$ close to 0 ), $\mathrm{NH}_{4}^{+}$accumulates in the ecosystem, leading to 
high nitrification flux, and subsequently to a high $\mathrm{NO}_{3}^{-}$ availability. Thus, despite the fact that plants prefer $\mathrm{NO}_{3}^{-}$, the availability of this $\mathrm{N}$ form remains relatively high because of the high nitrification flux.

As a result of these trends, the total availability of mineral $\mathrm{N}\left(\mathrm{NH}_{4}^{+}\right.$plus $\left.\mathrm{NO}_{3}^{-}\right)$is larger for extreme values of $\beta$ (either close to 0 or 1): the losses of mineral $\mathrm{N}$ are high while the productivity and plant biomass are low (fig. $2 A$, $2 B)$. Term $\beta_{\text {opt }}$ has an intermediate value that keeps both forms of mineral $\mathrm{N}$ to low levels, therefore preventing important $\mathrm{N}$ losses from the ecosystem and leading to a maximum plant biomass. Our results support conclusions from models considering only one limiting nutrient and reporting that the fewer nutrients are lost, the higher the plant biomass and productivity, as stated by Tilman's $R^{*}$ rule (Tilman 1985).

In our model, $\beta_{\text {opt }}$ corresponds to a "generalist" strategy, so that being specialized in one of the two $\mathrm{N}$ mineral forms is not optimal when considering primary productivity. Since $\beta$ affects in opposite ways the availability of both mineral $\mathrm{N}$ sources, being "specialized" in one of these $\mathrm{N}$ forms $(\beta<0.3$ or $\beta>0.9$; see fig. $2 B)$ deprives the plant of the resource that is not used. This resource then becomes more vulnerable to losses since it is not taken up by plants. Consequently, the total losses of mineral $\mathrm{N}$ are high, resulting in a low plant biomass and productivity.

We show in appendix $\mathrm{B}$ that $\beta_{\text {opt }}$ (optimal preference for $\mathrm{NH}_{4}^{+}$) varies depending on $\mathrm{N}$ inputs, $\mathrm{N}$ losses, and nitrification rates. More precisely, we show that in Pawnee, the higher the rates of nitrification and $\mathrm{NO}_{3}^{-}$deposition, the higher the plant productivity for plants exhibiting a high preference for $\mathrm{NO}_{3}^{-}$. Similarly, the higher the rates of $\mathrm{NO}_{3}^{-}$loss (for at least a twofold increase or more) and $\mathrm{NH}_{4}^{+}$deposition, the higher the plant productivity for plants exhibiting a high preference for $\mathrm{NH}_{4}^{+}$.

\section{Coexistence and Invasions}

Figure 3 displays the outcomes of a mutual invasion between two plants types $P_{1}$ and $P_{2}$ whose preferences for $\mathrm{NH}_{4}^{+}$versus $\mathrm{NO}_{3}^{-}$are equal to $\beta_{1}$ and $\beta_{2}$, respectively. When both plant types differ only by their preference for $\mathrm{NH}_{4}^{+}$ (fig. $3 A$ ), while being not specialized in $\mathrm{NH}_{4}^{+}$absorption $(\beta \leq 0.93)$, the one with the highest preference for $\mathrm{NH}_{4}^{+}$ invades and excludes the other (see zones $b$ and $c$ ): for example, if we consider an established population $P_{1}$ at $\beta_{1}=0.3$ being invaded by a type $P_{2}$ with $\beta_{2}=0.4$, this invader succeeds, excludes the resident population, and becomes the new resident population. Similarly, the plant type with the highest preference for $\mathrm{NH}_{4}^{+}$cannot be invaded by the other, that is, if a resident plant population $P_{1}$ exhibits a preference for $\mathrm{NH}_{4}^{+}$of $\beta_{1}=0.4$, an invader $P_{2}$ with a preference $\beta_{2}=0.3$ fails to invade the resident.
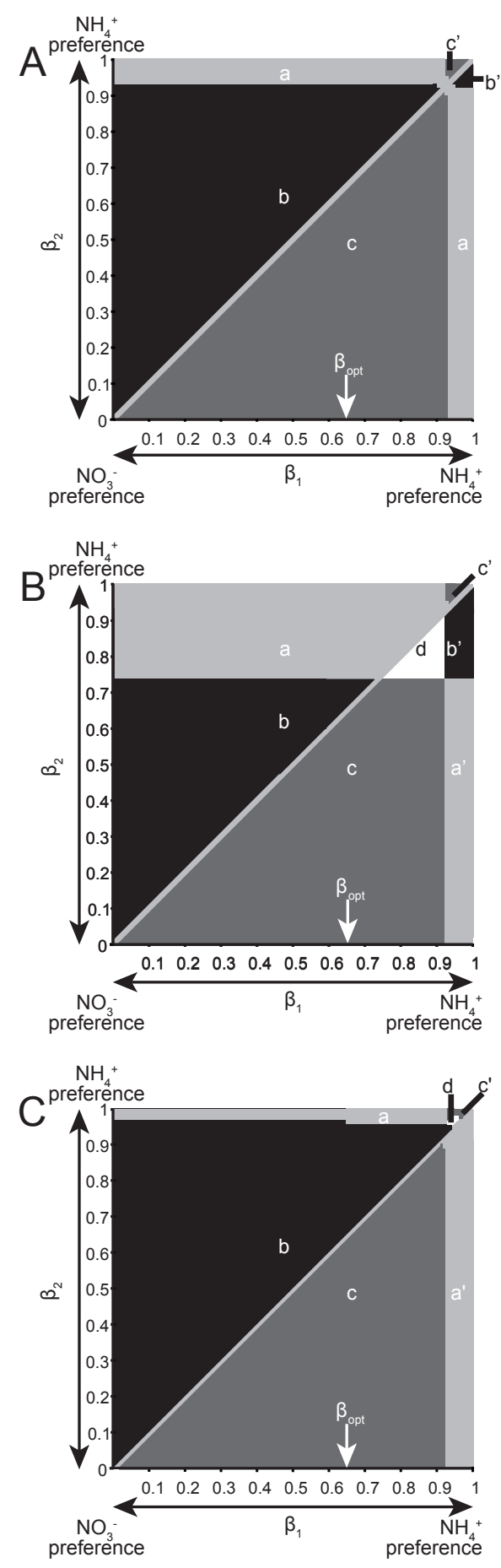

Figure 3: Patterns of invasion and coexistence between two plant types $\left(P_{1}\right.$ and $\left.P_{2}\right)$ for the Pawnee site $\left(A, P_{1}\right.$, and $P_{2}$ differ only in their preference for $\mathrm{NH}_{4}^{+}$vs. $\mathrm{NO}_{3}^{-} ; B, P_{2}$ stimulates nitrification; $C$, $P_{2}$ inhibits nitrification). Terms $\beta_{1}$ and $\beta_{2}$ are the $\mathrm{NH}_{4}^{+}$preferences for $P_{1}$ and $P_{2}$, respectively. Zones: light gray (a) $=$ coexistence; black (b) $=P_{2}$ wins the competition; dark gray (c) $=P_{1}$ wins the competition; white $(\mathrm{d})=$ no invasion and maintaining of residents. 
If both types are specialized in $\mathrm{NH}_{4}^{+}$absorption $(\beta \geq$ 0.93 in fig. $3 A$ ), then the plant type with the lowest preference for $\mathrm{NH}_{4}^{+}$invades the other, and cannot be invaded by the other (see zones $\mathrm{b}^{\prime}$ and $\mathrm{c}^{\prime}$ in fig. $3 A$ ). Coexistence occurs when a plant type specialized in $\mathrm{NH}_{4}^{+}$absorption $(\beta \geq 0.93)$ invades, or is invaded, by another one that is not specialized in $\mathrm{NH}_{4}^{+}$( $\beta \leq 0.93$ on fig. $3 A$; see zone a). When two plant types have exactly the same preference $\left(\beta_{1}=\beta_{2}\right)$, they obviously coexist. Note that the coexistence regions are entirely occupied by stable equilibria (numerically determined).

These results are in agreement with theoretical models showing that coexistence is possible for organisms that are dissimilar enough (Abrams 1996). Considering studies claiming that $n$ competitors can not coexist in a stable equilibrium on fewer than $n$ resources (Armstrong and McGehee 1980; Tilman 1985) our results suggest that $\mathrm{N}$ should not be considered as a single resource. Here, two plant types coexist on two mineral $\mathrm{N}$ forms. Some empirical studies have documented $\mathrm{N}$ partitioning between $\mathrm{N}$ mineral and organic forms (Miller and Bowman 2002; Weigelt et al. 2005; Fang et al. 2007) and also suggested that this partitioning could lead to coexistence.

When considering two plant types differing only by their preference for $\mathrm{NH}_{4}^{+}(\beta)$, the plant having the closest preference to the value that enables coexistence $(\beta \approx 0.93)$ always succeeds in invading the other. This suggests that from the population dynamics point of view, it can be expected that, in a community driven by competitive exclusion with local extinctions and repeated colonizations from a regional pool, plants' preferences will converge toward a value that enables coexistence $(\beta \approx 0.93$; see fig. $3 A$ ). This rationale should also be true on the evolutionary scale since figure $3 \mathrm{~A}$ can be assimilated to a pairwiseinvasibility plot (see articles on the adaptive dynamics methodology: Metz et al. 1996; Geritz et al. 1997). Indeed, when considering a rare mutant in a large population, evolution should push plant preference toward the same value $(\beta \approx 0.93)$. It is important to note that the value of $\beta$ (preference for $\mathrm{NH}_{4}^{+}$) enabling coexistence is significantly different from $\beta_{\mathrm{opt}}$, suggesting that the most productive plant is not necessarily the "best invader" and that evolution or species replacement does not optimize primary productivity (Boudsocq et al. 2011). Appendix D confirms that coexistence and complementarity between the resource use of the two plant types, lead to suboptimal values of primary productivity. Here, Tilman's $R^{*}$ rule is thus not respected. On one hand, a plant produces more biomass when relying on both $\mathrm{NH}_{4}^{+}$and $\mathrm{NO}_{3}^{-}$rather than on only one $\mathrm{N}$ form $\left(\beta_{\mathrm{opt}} \approx 0.65\right)$. On the other hand, plants should benefit from relying more on $\mathrm{NH}_{4}^{+}$than $\mathrm{NO}_{3}^{-}$(fig. $3 ; \beta>0.93$ ) since they (i) should resist to invasion and (ii) should succeed in invading plants differing only by their preference. This result does not support other studies stating that plants exhibiting the highest biomasses and productivities are those that are the most competitive on the most abundant form of $\mathrm{N}$ and vice versa (McKane et al. 2002; Houlton et al. 2007). This result also shows that coexistence based on $\mathrm{N}$ partition does not necessarily increase primary productivity or plant biomass. Although this result would require further analyses for a full interpretation, this confirms that mechanisms of coexistence influence the impact of biodiversity on ecosystem functioning (Mouquet et al. 2002).

\section{Nitrification Control by Plants and Its Effects on Invasion, Coexistence, and Exclusion}

Though mineral $\mathrm{N}$ is available in two different forms, these two forms are not independent: mineralization first releases $\mathrm{NH}_{4}^{+}$that is then converted in $\mathrm{NO}_{3}^{-}$during nitrification, so the abundance of $\mathrm{NO}_{3}^{-}$depends on both the abundance of $\mathrm{NH}_{4}^{+}$and the nitrification rate. This asymmetry between $\mathrm{NH}_{4}^{+}$and $\mathrm{NO}_{3}^{-}$should favor plants having a strong preference or being very competitive for the absorption of $\mathrm{NH}_{4}^{+}$, since these plants shunt the $\mathrm{N}$ cycle and take up mineral $\mathrm{N}$ before it is nitrified into $\mathrm{NO}_{3}^{-}$. However, atmospheric deposition of $\mathrm{NO}_{3}^{-}$constitutes an input into the system that cannot be shunted. Moreover, the competition between plants and microorganisms can also be stronger on $\mathrm{NH}_{4}^{+}$than $\mathrm{NO}_{3}^{-}$(Hodge et al. 2000), leading to a standing production of $\mathrm{NO}_{3}^{-}$by nitrifiers. This suggests that nitrification and its control by plants may play a central role in the outcome of competition for $\mathrm{NH}_{4}^{+}$and $\mathrm{NO}_{3}^{-}$between two species (Lata et al. 2004). To explore this, we consider two cases, the first one where one of the two plant types $\left(P_{2}\right)$ was able to stimulate nitrification (fig. $3 B$ ), and the second one where one of the two plant types $\left(P_{2}\right)$ was able to inhibit nitrification (fig. $3 C$ ). In both cases, we found new patterns of invasiveness and coexistence compared to the case where both types only differ by their preferences for $\mathrm{NH}_{4}^{+}$(fig. $3 A$ ).

Nitrification Stimulation. If $P_{2}$ is able to stimulate nitrification (fig. $3 B$ ), coexistence becomes possible over a greater range of combinations of plant preferences for $\mathrm{NH}_{4}^{+}$(see zone a, larger in $B$ than in $A$ ). The fact that coexistence is possible between two plant types having relatively low and similar preferences for $\mathrm{NH}_{4}^{+}$when nitrification is stimulated (see fig. $3 B$, zone a), is due to the fact that stimulation of nitrification balances the availability of both $\mathrm{N}$ mineral forms. Moreover, for a relatively large range of combinations of plants' preference, stimulating nitrification prevents invasion and exclusion between two plant types (see fig. 3B, zone d). When the type stimulating nitrification is the resident, then the availability 
of $\mathrm{NH}_{4}^{+}$is strongly decreased while $\mathrm{NO}_{3}^{-}$is greatly increased. An invader with a higher preference for $\mathrm{NH}_{4}^{+}$than the resident can not succeed in its invasion, because its preference does not enable it to take advantage of the new balance between both $\mathrm{N}$ mineral forms. Conversely, if the resident does not affect nitrification while the invader stimulates it, the invasion fails because the resident keeps the advantage given its higher preference for $\mathrm{NH}_{4}^{+}$. Here, the invader has too low a density to significantly affect the availability of $\mathrm{N}$ forms. This zone (d) can be considered as a "founder control" zone (Grime, 1998).

Hawkes and collaborators showed that several exotic annual grasses (Avena barbata and Bromus hordeaceous) were able to increase gross nitrification rates in the soil by a factor of 2 (Hawkes et al. 2005 ), and they suggested that such a control over nitrification gives a strong advantage in invading resident plants. This seems only partially in accordance with the results from our model, particularly when the considered plant has a higher preference for $\mathrm{NO}_{3}^{-}$than the resident does $\left(0.75<\beta_{2}<\beta_{1}<0.93\right.$; see fig. $3 B$, zone $\left.b^{\prime}\right)$. However, it can be supposed that a more local modeling approach would give stronger results since nitrification stimulation by a plant should influence only the vicinity of its own roots and then drastically modify the local environment of plants sharing its own rhizosphere. Taken together, our results confirm that the control of nitrification is crucial for the outcome of competition for $\mathrm{NH}_{4}^{+}$and $\mathrm{NO}_{3}^{-}$between plant types.

Nitrification Inhibition. The ability of $P_{2}$ (fig. 3C) to inhibit nitrification (i) allows this type to exclude the other even when its preference for $\mathrm{NH}_{4}^{+}$is very high (even for $0.93<\beta_{2}<0.97$; see the size of the zones a and $c^{\prime}$ in fig. $3 C$; cf. zones a and $c^{\prime}$ in fig. $3 A$ ), and (ii) prevents exclusion from an invasive type with lower preference for $\mathrm{NH}_{4}^{+}$when $P_{1}$ or $P_{2}$ have a high preference for $\mathrm{NH}_{4}^{+}$(see zone $\mathrm{d}$ in fig. $3 C)$.

Also, when considering the zone $\mathrm{d}$ in figure $3 C$, if the nitrification inhibiting plant is the resident, the availability of $\mathrm{NH}_{4}^{+}$is increased while $\mathrm{NO}_{3}^{-}$is decreased, so that a plant type that exhibits a lower preference for $\mathrm{NH}_{4}^{+}$than the resident cannot invade. Conversely, in the zone $\mathrm{d}$ in figure 3 , if the resident type does not affect nitrification, then an invader with the ability to inhibit nitrification, while having a higher preference for $\mathrm{NH}_{4}^{+}$, cannot invade the resident. This is because the invader does not exploit $\mathrm{NO}_{3}^{-}$even though the availability of this $\mathrm{N}$ form is relatively high.

\section{Factors Influencing $\mathrm{NO}_{3}^{-}$and $\mathrm{NH}_{4}^{+}$Uptake by Plants}

Some species are known to prefer $\mathrm{NH}_{4}^{+}$to $\mathrm{NO}_{3}^{-}$(Falkengren-Grerup and Lakkenborg-Kristensen 1994; Tavernier 2003; Zhao et al. 2009). However, it seems that sufficient empirical results are lacking for the derivation of general rules on plant preference as a function of the ecosystem they belong to, the physico-chemical conditions (e.g., atmospheric deposition, soil environmental conditions), their functional or taxonomic group, or their life stage. Are there some plant species that are able to use $\mathrm{NH}_{4}^{+}$and $\mathrm{NO}_{3}^{-}$indifferently (Hewins and Hyatt 2009)? Or, conversely, are there plants having a specific uptake capacity for each $\mathrm{N}$ form? It is likely that each plant species has a preference that depends on its genotype (rooting architecture, relationships with rhizospheric microorganisms, root uptake kinetics, transport and storage in plant cells, and ability to reduce $\mathrm{NO}_{3}^{-}$) and its environment (such as the temperature, $\mathrm{pH}$, humidity, relative abundances of $\mathrm{N}$ forms). In their article, Houlton et al. (2007) showed that some tropical plant species can switch their dominant $\mathrm{N}$ source $\left(\mathrm{NH}_{4}^{+}, \mathrm{NO}_{3}^{-}\right.$or dissolved organic $\left.\mathrm{N}\right)$ in response to changes in precipitation, by taking up the most available form of N. Similarly, Ashton et al. (2010) showed that some alpine plants can switch their main $\mathrm{N}$ source in function of the preference of their competitors for $\mathrm{N}$. This strongly suggests that some plant species might be plastic in their ability to take up the two forms of $\mathrm{N}$, but probably within a limited range determined by phylogenetic and energetic constraints. This plasticity should be taken into account in future models but we can consider for the moment that the $\beta$ (preference for $\mathrm{NH}_{4}^{+}$) of our model describes the realized preference in given conditions. Future models should also include a detailed analysis of the effect of the uptake rate $(u)$. Our model only allows for a constant intensity of uptake but plasticity in the total investment into $\mathrm{N}$ uptake could strengthen or attenuate the effects of $\beta$ on ecosystems properties as well as on the patterns of invasion and coexistence.

Finally, our model does not take into account $\mathrm{N}$ immobilization by soil microorganisms (Harrison et al. 2007). The consequences of this competition for mineral $\mathrm{N}$ between microbes and plants have already been investigated in our previous model (Boudsocq et al. 2009), and we found that at equilibrium state, immobilization of $\mathrm{N}$ by microorganisms does not affect the availability of both $\mathrm{N}$ forms for plants. This general result still holds in this version of the model. However, we can also suppose that the microorganisms competitiveness and preference for $\mathrm{NH}_{4}^{+}$and $\mathrm{NO}_{3}^{-}$can have a significant impact on the availability of these $\mathrm{N}$ forms for plants and thus on the preference for $\mathrm{NH}_{4}^{+}$versus $\mathrm{NO}_{3}^{-}$of plants. Better knowledge and understanding of the competitive interactions between plants and microbes for mineral $\mathrm{N}$ uptake, and their preferences for mineral $\mathrm{N}$ forms, could significantly improve our assessment of the optimal preference of plants for $\mathrm{NH}_{4}^{+}$versus $\mathrm{NO}_{3}^{-}$in a given ecosystem and allow speculation on its potential evolution in a global change context. 


\section{Perspectives}

Our results point out the large and overlooked potentia $\rightarrow$ consequences of plant preference for $\mathrm{NH}_{4}^{+}$versus $\mathrm{NO}_{3}^{-}$on terrestrial ecosystem functioning and plant community structure. To address this crucial point, we urgently neec to experimentally assess the preference for $\mathrm{NH}_{4}^{+}$versus $\mathrm{NO}_{3}^{-}$of a large number of plant species and try to relate it with plant life stages and phylogeny or ecosystem properties. It would also enable assessing the plasticity of plant: in their preference and their productivity, following what has been done on some species (Maire et al. 2009).

Determining the link between plants' preference for either form of $\mathrm{N}$ and their own productivity would be $\mathrm{o}_{-} \rightarrow$ particular interest for the current and future management of agrosystems. For example, our results suggest that plant production and mineral $\mathrm{N}$ losses depend on plant preference for $\mathrm{NH}_{4}^{+}$versus $\mathrm{NO}_{3}^{-}$, on nitrification rates (and thus on plant ability to inhibit or stimulate nitrification) and on external inputs of the two mineral $\mathrm{N}$ forms (app. B). Our model could help increasing crop yield and de creasing $\mathrm{N}$ losses by choosing fertilization practices and selecting the relevant varieties of plants for their preference for $\mathrm{NO}_{3}^{-}$or $\mathrm{NH}_{4}^{+}$and their capacity to control nitrification (Subbarao et al. 2006; Maire et al. 2009). This is of paramount importance because modern agriculture urgently ${ }^{r}$ requires more sustainability and reducing $\mathrm{N}$ losses (Tilman et al. 2002), as mineral fertilization leads to the degradation of many terrestrial and aquatic ecosystems, and as thi $\rightarrow$ industrial production of mineral $\mathrm{N}$ is based on nonrenewable energy resources.
Armstrong, R. A., and R. McGehee. 1980. Competitive exclusion. American Naturalist 115:151-170.

Ashton, I. W., A. E. Miller, W. D. Bowman, and K. N. Suding. 2010. Niche complementarity due to plasticity in resource use: plant partitioning of chemical $\mathrm{N}$ forms. Ecology 91:3252-3260.

Barot, S., A. Ugolini, and F. Bekal Brikci. 2007. When do soil decomposers and ecosystem engineers enhance plant production? Functional Ecology 21:1-10.

Begon, M., J. L. Harper, and C. R. Townsend. 1998. Ecology. 3rd ed. Blackwell, Oxford.

Boudsocq, S., S. Barot, and N. Loeuille. 2011. Evolution of nutrient acquisition: when adaptation fills the gap between contrasting ecological theories. Proceedings of the Royal Society B: Biological Sciences 278:449-457.

Boudsocq, S., J.-C. Lata, J. Mathieu, L. Abbadie, and S. Barot. 2009. Modelling approach to analyse the effects of nitrification inhibition on primary production. Functional Ecology 23:220-230.

$\rightarrow$ Bowman, D. M. J. S., J. K. Balch, P. Artaxo, W. J. Bond, J. M. Carlson, M. A. Cochrane, C. M. D'Antonio, et al. 2009. Fire in the earth system. Science 324:481-484.

Brady, N. C., and R. C. Weil. 2001. The nature and properties of soils. 13th ed. Prentice-Hall, Upper Saddle River, NJ.

Britto, D. T., M. Y. Siddiqi, A. D. M. Glass, and H. J. Kronzucker. 2001. Futile transmembrane $\mathrm{NH}_{4}^{+}$cycling: a cellular hypothesis to explain ammonium toxicity in plants. Proceedings of the National Academy of Sciences of the USA 98:4255-4258.

$\rightarrow$ Chesson, P. 2000. Mechanisms of maintenance of species diversity. Annual Review of Ecology, Evolution, and Systematics 31:343-366.

de Graaf, M. C. C., R. Bobbink, J. G. M Roelofs, and P. J. M Verbeek. 1998. Differential effects of ammonium and nitrate on three heathland species. Plant Ecology 135:185-196.

Falkengren-Grerup, U., and H. Lakkenborg-Kristensen. 1994. Importance of ammonium and nitrate to the performance of herblayer species from deciduous forests in southern Sweden. Environmental and Experimental Botany 34:31-38.

$\rightarrow$ Fang, Y. Y., O. Babourina, Z. Rengel, X. E. Yang, and P. M. Pu. 2007. Ammonium and nitrate uptake by the floating plant Landoltia punctata. Annals of Botany 99:365-370.

\section{Acknowledgments}

The authors thank E. Rochelle-Newall for her expertise as a native English speaker and J. Pastor and an anonymous reviewer for their helpful and constructive comments. Thi $\rightarrow$ research has been supported by the French Agence Nationale de la Recherche projects CIS "3Worlds" (20082011) and JC05_52230 "SolEcoEvo" (2005-2008).

\section{Literature Cited}

$\rightarrow$ Frank, D. A., and P. M. Groffman. 2009. Plant rhizospheric N processes: what we don't know and why we should care. Ecology 90: 1512-1519.

Galloway, J. N., F. J. Dentener, D. G. Capone, E. W. Boyer, R. W. Howarth, S. P. Seitzinger, G. P. Asner, et al. 2004. Nitrogen cycles: past, present, and future. Biogeochemistry 70:153-226.

$\rightarrow$ Geritz, S. A. H., J. A. J. Metz, E. Kisdi, and G. Meszena. 1997. Dynamics of adaptation and evolutionary branching. Physical Review Letters 78:2024-2027.

$\rightarrow$ Grime, J. P. 1998. Benefits of plant diversity to ecosystems: immediate, filter and founder effects. Journal of Ecology 86:902-910.

$\rightarrow$ Aanderud, Z. T., and C. S. Bledsoe. 2009. Preferences for ${ }^{15} \mathrm{~N}-$ ammonium, ${ }^{15} \mathrm{~N}$-nitrate, and ${ }^{15} \mathrm{~N}$-glycine differ among dominant exotic and subordinate native grasses from a California oak woodland. Environmental and Experimental Botany 65:205-209.

Abbadie, L. 2006. Nitrogen inputs to and outputs from the soil-plant system. Pages 255-275 in L. Abbadie, J. Gignoux, X. Roux, and M. Lepage, eds. Lamto: structure, functioning, and dynamics of $: \rightarrow$ savanna ecosystem. Springer, New York.

$\rightarrow$ Abrams, P. A. 1996. Limits to the similarity of competitors under

hierarchical lottery competition. American Naturalist 148:211-219 $\rightarrow$ Hodge, A., C. D. Campbell, and A. H. Fitter. 2001. An arbuscular
Harrison, K. A., R. Bol, and R. D. Bardgett. 2007. Preferences for different nitrogen forms by coexisting plant species and soil microbes: comment. Ecology 88:989-999.

$\rightarrow$ Hawkes, C. V., I. F. Wren, D. J. Herman, and M. K. Firestone. 2005. Plant invasion alters nitrogen cycling by modifying the soil nitrifying community. Ecology Letters 8:976-985.

Hewins, D. B., and L. A. Hyatt. 2009. Flexible N uptake and assimilation mechanisms may assist biological invasion by Alliaria petiolata. Biological Invasions 12:2639-2647. 
mycorrhizal fungus accelerates decomposition and acquires nitrogen directly from organic material. Nature 413:297-299.

$\rightarrow$ Hodge, A., D. Robinson, and A. H. Fitter. 2000. Are microorganism $\rightarrow$ more effective than plants at competing for nitrogen? Trends in Plant Science 5:304-308.

$\rightarrow$ Holland, E. A., F. J. Dentener, B. H. Braswell, and J. M. Sulzman $\rightarrow$ 1999. Contemporary and pre-industrial global reactive nitrogen budgets. Biogeochemistry 46:7-43.

$\rightarrow$ Holt, R. D. 2008. Perspectives on resource pulses. Ecology 89:671681.

$\rightarrow$ Houlton, B. Z., D. M. Sigman, E. A. G. Schuur, and L. O. Hedin. 2007. A climate-driven switch in plant nitrogen acquisition within tropical forest communities. Proceedings of the National Academ, of Sciences of the USA 104:8902-8906.

$\rightarrow$ Kahmen, A., W. Wanek, and N. Buchmann. 2008. Foliar $\delta^{15} \mathrm{~N}$ value characterize soil $\mathrm{N}$ cycling and reflect nitrate or ammonium preference of plants along a temperate grassland gradient. Oecologia (Berlin) 156:861-870.

$\rightarrow$ Lata, J.-C., V. Degrange, X. Raynaud, P.-A. Maron, R. Lensi, and L. Abbadie. 2004. Grass populations control nitrification in savanna $\rightarrow$ soils. Functional Ecology 18:605-611.

$\rightarrow$ Lata, J.-C., J. Durand, R. Lensi, and L. Abbadie. 1999. Stable coexistence of contrasted nitrification statuses in a wet tropical savanna ecosystem. Functional Ecology 13:762-768.

$\rightarrow$ Lata, J.-C., K. Guillaume, V. Degrange, L. Abbadie, and R. Lensi. 2000. Relationships between root density of the African grass $H y$ parrhenia diplandra and nitrification at the decimetric scale: an inhibition-stimulation balance hypothesis. Proceedings of the Royal Society B: Biological Sciences 267:595-600.

$\rightarrow$ Maire, V., N. Gross, L. da Silveira Pontes, C. Picon-Cochard, and J.F. Soussana. 2009. Trade-off between root nitrogen acquisition ana shoot nitrogen utilization across 13 co-occurring pasture grase species. Functional Ecology 23:668-679.

Marschner, H. 2008. Mineral nutrition of higher plants. 2nd ed. Academic Press, London.

Marschner, P., and Z. Rengel. 2007. Nutrient cycling in terrestrial ecosystems. Springer, Heidelberg.

$\rightarrow$ McKane, R. B., L. C. Johnson, G. R. Shaver, K. J. Nadelhoffer, E. B. Rastetter, B. Fry, A. E. Giblin, et al. 2002. Resource-based nicher provide a basis for plant species diversity and dominance in arctic tundra. Nature 415:68-71.

$\rightarrow$ Menge, D. N. L., S. A. Levin, and L. O. Hedin. 2008. Evolutionary tradeoffs can select against nitrogen fixation and thereby maintain nitrogen limitation. Proceedings of the National Academy of Sci ences of the USA 105:1573-1578.

Metz, J. A. J., S. A. H. Geritz, G. Meszena, F. J. A. Jacobs, and J. S. van Heerwaarden. 1996. Adaptive dynamics, a geometrical study of the consequences of nearly faithful reproduction. Pages 183231 in S. J. van Strien and S. M. Verduyn Lunel, eds. Stochastic and spatial structures of dynamical systems. North Holland Amsterdam.

$\rightarrow$ Miller, A. E., and W. D. Bowman. 2002. Variations in nitrogen-15 natural abundance and nitrogen uptake traits among co-occuring alpine species: do species partition by nitrogen form? Oecologia (Berlin) 130:609-616.

$\rightarrow$ Mouquet, N., J. L. Moore, and M. Loreau. 2002. Plant species richness and community productivity: why the mechanism that promotes coexistence matters. Ecology Letters 5:56-65.

Pacala, S. W., and D. Tilman. 1994. Limiting similarity in mechanistic and spatial models of plant competition in heterogeneous environments. American Naturalist 143:222-257.

Rossiter-Rachor, N. A., S. A. Setterfield, M. M Douglas, L. B. Hutley, G. D. Cook, and S. Schmidt. 2009. Invasive Andropogon gayanus (gamba grass) is an ecosystem transformer of nitrogen relations in Australian savanna. Ecological Applications 19:1546-1560.

Salsac, L., S. Chaillou, J.-F. Morot-Gaudry, C. Lesaint, and E. Jolivoe. 1987. Nitrate and ammonium nutrition in plants. Plant Physiology and Biochemistry 25:805-812.

Schimel, J. P., and J. Bennett. 2004. Nitrogen mineralization: challenges of a changing paradigm. Ecology 85:591-602.

Subbarao, G. V., O. Ito, K. L. Sahrawat, W. L. Berry, K. Nakahara, T. Ishikawa, T. Watanabe, K. Suenaga, M. Rondon, and I. M. Rao. 2006. Scope and strategies for regulation of nitrification in agricultural systems: challenges and opportunities. Critical Reviews in Plant Sciences 25:303-335.

Subbarao, G. V., M. Rondon, O. Ito, T. Ishikawa, I. M. Rao, K. Nakahara, C. E. Lascano, and W. L. Berry. 2007a. Biological nitrification inhibition (BNI)-is it a widespread phenomenon? Plant and Soil 294:5-18.

Subbarao, G. V., H. Y. Wang, O. Ito, K. Nakahara, and W. L. Berry. $2007 b$. $\mathrm{NH}_{4}^{+}$triggers the synthesis and release of biological nitrification inhibition compounds in Brachiaria humidicola roots. Plant and Soil 290:245-257.

Tavernier, V. 2003. Interactions entre structures racinaires et cycle de l'azote en savane africaine. PhD thesis. Institut National Agronomique Paris-Grignon, Paris.

$\rightarrow$ Tilman, D. 1985. The resource-ratio hypothesis of plant succession. American Naturalist 125:827-852.

Tilman, D., K. G. Cassman, P. A. Matson, R. Naylor, and S. Polasky. 2002. Agricultural sustainability and intensive production practices. Nature 418:671-677.

$\rightarrow$ Vitousek, P. M., K. G. Cassman, C. C. Cleveland, T. E. Crews, C. B. Field, N. B. Grimm, R. W. Howarth, et al. 2002. Towards an ecological understanding of biological nitrogen fixation. Biogeochemistry 57/58:1-45.

Vitousek, P. M., and R. W. Howarth. 1991. Nitrogen limitation on land and in the sea: how can it occur? Biogeochemistry 13:87-115.

$\rightarrow$ Weigelt, A., R. Bol, and R. D. Bardgett. 2005. Preferential uptake of soil nitrogen forms by grassland species. Oecologia (Berlin) 142: $627-635$.

$\rightarrow$ Williams, L. E., and A. J. Miller. 2001. Transporters responsible for the uptake and partitioning of nitrogenous solutes. Annual Review of Plant Physiology and Plant Molecular Biology 52:659-688.

Woodmansee, R. G., J. L. Dodd, R. A. Bowman, F. E. Clark, and C. E. Dickinson. 1978. Nitrogen budget of a shortgrass prairie ecosystem. Oecologia (Berlin) 34:363-376.

Zhao, X. Q., R. F. Shen, and Q. B. Sun. 2009. Ammonium under solution culture alleviates aluminum toxicity in rice and reduces aluminum accumulation in roots compared with nitrate. Plant and Soil 315:107-121.

Associate Editor: James J. Elser Editor: Mark A. McPeek 


\section{Appendix A from S. Boudsocq et al., "Plant Preference for Ammonium versus Nitrate: A Neglected Determinant of Ecosystem Functioning?" (Am. Nat., vol. 180, no. 1, p. 60)}

\section{Analytical Studies}

\section{Existence and Conditions of a Single Possible Equilibrium}

Here is the model set of differential equations for one plant type that does not affect nitrification.

$$
\begin{aligned}
\frac{d P}{d t} & =\beta u N_{\mathrm{A}} P+(1-\beta) u N_{\mathrm{N}} P-\left(d+l_{P}-f\right) P, \\
\frac{d D}{d t} & =R_{D}+d P-\left(m+l_{D}\right) D, \\
\frac{d N_{\mathrm{A}}}{d t} & =R_{\mathrm{A}}+m D-\beta P u N_{\mathrm{A}}-\left(l_{N_{\mathrm{A}}}+n\right) N_{\mathrm{A}}, \\
\frac{d N_{\mathrm{N}}}{d t} & =R_{\mathrm{N}}+n N_{\mathrm{A}}-\left[(1-\beta) u P+l_{N_{\mathrm{N}}}\right] N_{\mathrm{N}} .
\end{aligned}
$$

To determine the effects of $\beta$ on ecosystem properties, we determine the mathematical equations corresponding to the compartment steady states by setting the system of differential equations to 0 . We can then express some of the model compartments as functions of the others:

$$
\begin{aligned}
D^{*} & =\frac{R_{D}+d P^{*}}{m+l_{D}}, \\
N_{\mathrm{A}}^{*} & =\frac{R_{\mathrm{A}}+m D^{*}}{\beta u P^{*}+l_{N_{\mathrm{A}}}+n}, \\
N_{\mathrm{N}}^{*} & =\frac{R_{\mathrm{N}}+n N_{\mathrm{A}}^{*}}{(1-\beta) u P^{*}+l_{N_{\mathrm{N}}}} .
\end{aligned}
$$

Being the most constraining variable, when $P$ is positive, all other compartments are positive. After some algebraic computations, we obtain a polynomial equation of the second order for the $P^{*}$ compartment:

$$
a P^{2}+b P+c=0
$$

where

$$
\begin{aligned}
a= & {\left[\frac{m}{m+l_{D}} d-\left(d+l_{P}-f\right)\right] u^{2} \beta(1-\beta), } \\
b= & {\left[\beta u l_{N_{\mathrm{N}}}+(1-\beta) u n\right]\left[\frac{m}{m+l_{D}} d-\left(d+l_{P}-f\right)\right] } \\
& +(1-\beta) u\left[\beta u\left(\frac{m}{m+l_{D}} R_{D}+R_{\mathrm{A}}+R_{\mathrm{N}}\right)-l_{N_{\mathrm{A}}}\left(d+l_{P}-f\right)\right], \\
c= & {\left[\beta u l_{N_{\mathrm{N}}}+(1-\beta) u n\right]\left(\frac{m}{m+l_{D}} R_{D}+R_{\mathrm{A}}\right)+\left[(1-\beta) u R_{\mathrm{N}}-l_{N_{\mathrm{N}}}\left(d+l_{P}-f\right)\right]\left(l_{N_{\mathrm{A}}}+n\right) . }
\end{aligned}
$$


Consequently, two solutions are possible:

$$
\begin{aligned}
& P_{X}=\frac{-b-\sqrt{b^{2}-4 a c}}{2 a}, \\
& P_{Y}=\frac{-b+\sqrt{b^{2}-4 a c}}{2 a} .
\end{aligned}
$$

Mathematically, there can be zero ( $a$ and $c$ are positive), one ( $a$ and $c$ have opposite signs), or two ( $a$ and $c$ are negative) positive equilibria for $P^{*}$. However, it is important to note that $c$ must be positive for the plants to invade: from equations (A1)-(A4), it is possible to determine the condition under which the plants can invade the plantless equilibrium.

From equations (A5)-(A7), we have

$$
\begin{aligned}
D_{(P \rightarrow 0)}^{*} & =\frac{R_{D}+d}{m+l_{D}}, \\
N_{\mathrm{A}(P \rightarrow 0)}^{*} & =\frac{R_{\mathrm{A}}+m D^{*}}{l_{N_{\mathrm{A}}}+n}=\frac{R_{\mathrm{A}}+m\left[\left(R_{D}+d\right) /\left(m+l_{D}\right)\right]}{l_{N_{\mathrm{A}}}+n}, \\
N_{\mathrm{N}(P \rightarrow 0)}^{*} & =\frac{R_{\mathrm{N}}+n N_{\mathrm{A}}^{*}}{l_{N_{\mathrm{N}}}}=\frac{R_{\mathrm{N}}+n\left\{R_{\mathrm{A}}+m\left[\left(R_{D}+d\right) /\left(m+l_{D}\right)\right]\right\} /\left(l_{N_{\mathrm{A}}}+n\right)}{l_{N_{\mathrm{N}}}} .
\end{aligned}
$$

So that from equation (A1), we obtain the following condition:

$$
\begin{aligned}
\left(\frac{d P}{d t}>0\right)_{P \rightarrow 0} \Leftrightarrow & \beta u N_{\mathrm{A}(P \rightarrow 0)}^{*}+(1-\beta) u N_{\mathrm{N}(P \rightarrow 0)}^{*}-\left(d+l_{P}-f\right)>0, \\
\left(\frac{d P}{d t}>0\right)_{P \rightarrow 0} \Leftrightarrow & \beta u\left\{\frac{R_{\mathrm{A}}+m\left[\left(R_{D}+d\right) /\left(m+l_{D}\right)\right]}{l_{N_{\mathrm{A}}}+n}\right\} \\
& +(1-\beta) u \frac{R_{\mathrm{N}}+n\left(\left\{R_{\mathrm{A}}+m\left[\left(R_{D}+d\right) /\left(m+l_{D}\right)\right]\right\} /\left(l_{N_{\mathrm{A}}}+n\right)\right)}{l_{N_{\mathrm{N}}}}-\left(d+l_{P}-f\right)>0, \\
\left(\frac{d P}{d t}>0\right)_{P \rightarrow 0} \Leftrightarrow & {\left[\beta u l_{N_{\mathrm{N}}}+(1-\beta) u n\right]\left(\frac{m}{m+l_{D}} R_{D}+R_{\mathrm{A}}\right)+\left[(1-\beta) u R_{\mathrm{N}}-l_{N_{\mathrm{N}}}\left(d+l_{P}-f\right)\right]\left(l_{N_{\mathrm{A}}}+n\right)>0, } \\
\left(\frac{d P}{d t}>0\right)_{P \rightarrow 0} \Leftrightarrow & c>0 .
\end{aligned}
$$

Since $c$ must be positive for plants to invade, note that a negative $a$ is required to have a stable plant existence equilibrium. If $a>0, \mathrm{~N}$ fixation is so high that the system accumulates infinitely $\mathrm{N}$ (see eq. [A8]), so that the system can never reach equilibrium (see equilibrium conditions in Boudsocq et al. 2011). When the condition from equation (A11) is fulfilled and when $a<0$ (which is the case for the Pawnee and Lamto ecosystems), only one of the two solutions for the $P^{*}$ equilibrium is positive.

\section{Variations of the Equilibrium Stocks with Respect to $\beta$}

From equilibrium equations (A5)-(A7), we can study the derivatives of the corresponding compartments with respect to $\beta$. For $D^{*}$, we have

$$
\begin{aligned}
& \frac{d D^{*}}{d \beta}=\frac{\partial D^{*}}{\partial P^{*}} \frac{d P^{*}}{d \beta}, \\
& \frac{d D^{*}}{d \beta}=\frac{d}{m+l_{D}} \frac{d P^{*}}{d \beta} .
\end{aligned}
$$


This implies that $D^{*}$ and $P^{*}$ always vary in a similar way when $\beta$ changes. For $N_{\mathrm{A}}^{*}$, we have

$$
\begin{aligned}
& \frac{d N_{\mathrm{A}}^{*}}{d \beta}=\frac{\partial N_{\mathrm{A}}^{*}}{\partial \beta}+\frac{\partial N_{\mathrm{A}}^{*}}{\partial P^{*}} \frac{d P^{*}}{d \beta}+\frac{\partial N_{\mathrm{A}}^{*}}{\partial D^{*}} \frac{d D^{*}}{d \beta} \\
& \frac{d N_{\mathrm{A}}^{*}}{d \beta}=\frac{\partial N_{\mathrm{A}}^{*}}{\partial \beta}+\frac{d P^{*}}{d \beta}\left(\frac{\partial N_{\mathrm{A}}^{*}}{\partial P^{*}}+\frac{d}{m+l_{D}} \frac{\partial N_{\mathrm{A}}^{*}}{\partial D^{*}}\right) .
\end{aligned}
$$

And for $N_{\mathrm{N}} *$, we have

$$
\frac{d N_{\mathrm{N}}^{*}}{d \beta}=\frac{\partial N_{\mathrm{N}}^{*}}{\partial \beta}+\frac{\partial N_{\mathrm{N}}^{*}}{\partial P^{*}} \frac{d P^{*}}{d \beta}+\frac{\partial N_{\mathrm{N}}^{*}}{\partial N_{\mathrm{A}}^{*}} \frac{d N_{\mathrm{A}}^{*}}{d \beta} .
$$

Now, let us define the following term,

$$
K_{1}=-\frac{1}{\beta u P^{*}+l_{N_{\mathrm{A}}}+n},
$$

and note that $K_{1}$ is always negative. From the $N_{\mathrm{A}}$ * equilibrium expression (eq. [A6]), we find

$$
\frac{\partial N_{\mathrm{A}}^{*}}{\partial \beta}=-\frac{u N_{\mathrm{A}}^{*} P^{*}}{\beta u P^{*}+l_{N_{\mathrm{A}}}+n}=u N_{\mathrm{A}}^{*} P^{*} K_{1}
$$

this term is always negative;

$$
\frac{\partial N_{\mathrm{A}}^{*}}{\partial P^{*}}=-\frac{u N_{\mathrm{A}}^{*} \beta}{\beta u P^{*}+l_{N_{\mathrm{A}}}+n}=u N_{\mathrm{A}}^{*} \beta K_{1} ;
$$

this term is always negative; and

$$
\frac{\partial N_{\mathrm{A}}^{*}}{\partial D^{*}}=\frac{m}{\beta u P^{*}+l_{N_{\mathrm{A}}}+n}=-m K_{1}
$$

this term is always positive.

So we have

$$
\begin{aligned}
& \frac{d N_{\mathrm{A}}^{*}}{d \beta}=\frac{\partial N_{\mathrm{A}}^{*}}{\partial \beta}+\frac{d P^{*}}{d \beta}\left(\frac{\partial N_{\mathrm{A}}^{*}}{\partial P^{*}}+\frac{d}{m+l_{D}} \frac{\partial N_{\mathrm{A}}^{*}}{\partial D^{*}}\right), \\
& \frac{d N_{\mathrm{A}}^{*}}{d \beta}=u N_{\mathrm{A}}^{*} P^{*} K_{1}+\frac{d P^{*}}{d \beta}\left(u N_{\mathrm{A}}^{*} \beta K_{1}-\frac{d}{m+l_{D}} K_{1} m\right), \\
& \frac{d N_{\mathrm{A}}^{*}}{d \beta}=K_{1}\left[u N_{\mathrm{A}}^{*} P^{*}+\frac{d P^{*}}{d \beta}\left(u N_{\mathrm{A}}^{*} \beta-\frac{m}{m+l_{D}} d\right)\right] .
\end{aligned}
$$

While $K_{1}$ is always negative, the term in parentheses may be positive or negative. Because of the $u N_{\AA}^{*} P^{*}$ term, $P^{*}$ and $N_{\AA}^{*}$ do not vary in a strictly similar way when $\beta$ changes.

Then, let us define the following term:

$$
K_{2}=-\frac{1}{(1-\beta) u P^{*}+l_{N_{\mathrm{N}}}} .
$$

Note that $K_{2}$ is always negative. 
From the $N_{\mathrm{N}}^{*}$ equilibrium expression (eq. [A7]), we find

$$
\begin{aligned}
& \frac{\partial N_{\mathrm{N}}^{*}}{\partial \beta}=\frac{u N_{\mathrm{N}}^{*} P^{*}}{(1-\beta) u P^{*}+l_{N_{\mathrm{N}}}}=-u N_{\mathrm{N}}^{*} P^{*} K_{2}, \\
& \frac{\partial N_{\mathrm{N}}^{*}}{\partial P^{*}}=-\frac{u N_{\mathrm{N}}^{*}(1-\beta)}{(1-\beta) u P^{*}+l_{N_{\mathrm{N}}}}=u N_{\mathrm{N}}^{*}(1-\beta) K_{2}, \\
& \frac{\partial N_{\mathrm{N}}^{*}}{\partial N_{\mathrm{A}}^{*}}=\frac{n}{(1-\beta) u P^{*}+l_{N_{\mathrm{N}}}}=-n K_{2} .
\end{aligned}
$$

Note that these three derivatives are always positive, negative, and positive, respectively.

We have

$$
\begin{aligned}
& \frac{d N_{\mathrm{N}}^{*}}{d \beta}=\frac{\partial N_{\mathrm{N}}^{*}}{\partial \beta}+\frac{\partial N_{\mathrm{N}}^{*}}{\partial P^{*}} \frac{d P^{*}}{d \beta}+\frac{\partial N_{\mathrm{N}}^{*}}{\partial N_{\mathrm{A}}^{*}} \frac{d N_{\mathrm{A}}^{*}}{d \beta} \\
& \frac{d N_{\mathrm{N}}^{*}}{d \beta}=-u N_{\mathrm{N}}^{*} P^{*} K_{2}+u N_{\mathrm{N}}^{*}(1-\beta) K_{2} \frac{d P^{*}}{d \beta}-n K_{2} \frac{d N_{\mathrm{A}}^{*}}{d \beta} .
\end{aligned}
$$

Using equation (A13), we obtain

$$
\frac{d N_{\mathrm{N}}^{*}}{d \beta}=K_{2}\left\{\left[u N_{\mathrm{N}}^{*}(1-\beta)-n K_{1}\left(u N_{\mathrm{A}}^{*} \beta-\frac{m}{m+l_{D}} d\right)\right] \frac{d P^{*}}{d \beta}-u P^{*}\left(n K_{1} N_{\mathrm{A}}^{*}+N_{\mathrm{N}}^{*}\right)\right\} .
$$

Again, note that while $K_{2}$ is always negative, the whole term in parentheses may be positive or negative. Because of the term $u P^{*}\left(n K_{1} N_{\mathrm{A}}^{*}+N_{\mathrm{N}}^{*}\right), N_{\mathrm{N}}^{*}$ and $P^{*}$ do not vary in a strictly similar way when $\beta$ changes.

\section{Conditions for an Increase of the $N_{\mathrm{A}}$ Compartment Size with $\beta$}

We look for a condition enabling an increase of the $N_{\mathrm{A}}^{*}$ compartment when $\beta$ increases:

$$
\frac{d N_{\mathrm{A}}^{*}}{d \beta}>0 \Leftrightarrow K_{1}\left[u N_{\mathrm{A}}^{*} P^{*}+\frac{d P^{*}}{d \beta}\left(u N_{\mathrm{A}}^{*} \beta-\frac{m}{m+l_{D}} d\right)\right]>0 .
$$

Since $\mathrm{K}_{1}$ is always negative,

$$
\frac{d N_{\mathrm{A}}^{*}}{d \beta}>0 \Leftrightarrow u N_{\mathrm{A}}^{*} P^{*}+\frac{d P^{*}}{d \beta}\left(u N_{\mathrm{A}}^{*} \beta-\frac{m}{m+l_{D}} d\right)<0 .
$$

Two situations are then possible. If (i) $u N_{A}^{*} \beta-\left[m /\left(m+l_{D}\right)\right] d>0$, then it is necessary that the plant biomass decreases with $\beta$ for $N_{\mathrm{A}}^{*}$ to increase with $\beta$ :

$$
\frac{d N_{\mathrm{A}}^{*}}{d \beta}>0 \Leftrightarrow \frac{d P^{*}}{d \beta}<\frac{u N_{\mathrm{A}}^{*} P^{*}}{\left[m /\left(m+l_{D}\right)\right] d-u N_{\mathrm{A}}^{*} \beta}<0 .
$$

(ii) If $u N_{\mathrm{A}}^{*} \beta-\left[m /\left(m+l_{D}\right)\right] d<0$, then it is necessary that the plant biomass increases with $\beta$ for $N_{\mathrm{A}}^{*}$ to increase with $\beta$ :

$$
\frac{d N_{\mathrm{A}}^{*}}{d \beta}>0 \Leftrightarrow \frac{d P^{*}}{d \beta}>\frac{u N_{\mathrm{A}}^{*} P^{*}}{\left[m /\left(m+l_{D}\right)\right] d-u N_{\mathrm{A}}^{*} \beta}>0 .
$$

Intuitively, condition (A15.1) has more chances to be verified if the term $u N_{\mathrm{A}}^{*} \beta$ is high and/or if the terms $u N_{\mathrm{A}}^{*} P^{*}$ and $m /\left(m+l_{D}\right) d$ are low. It means that the higher the plant preference for $\mathrm{NH}_{4}^{+}$, the lower the plant biomass and the recycling efficiency of dead plant biomass into $\mathrm{NH}_{4}^{+}$, the higher the probability to see $N_{\mathrm{A}}^{*}$ increase with $\beta$. This condition has also more chances to be verified if $P^{*}$ decreases quickly with $\beta$ and for high values of $\beta$.

On the other hand, condition (A15.2) has more chances to be verified if the terms $u N_{\mathrm{A}}^{*} \beta$ and $u N_{\mathrm{A}}^{*} P^{*}$ are low and/or if the term $m /\left(m+l_{D}\right) d$ is high. It means that the lower the $\mathrm{NH}_{4}^{+}$stock, the plant biomass, the plant preference for $\mathrm{NH}_{4}^{+}$, and the higher the recycling efficiency of dead plant biomass into $\mathrm{NH}_{4}^{+}$, the higher the probability to see $N_{\mathrm{A}}^{*}$ increase with $\beta$. This condition has more chance to be verified if $P^{*}$ increases quickly with $\beta$ and for low values of $\beta$. 


\section{Maximization of Primary Productivity When Plant Biomass Is Maximized}

Given the following primary productivity equation and equation (1),

$$
\phi^{*}=\left[\beta u N_{\mathrm{A}}^{*}+(1-\beta) u N_{\mathrm{N}}^{*}+f\right] P^{*} .
$$

At equilibrium, when $d P / d t=0$, we obtain

$$
\left[\beta u N_{\mathrm{A}}^{*}+(1-\beta) u N_{\mathrm{N}}^{*}+f\right] P^{*}=\left(d+l_{P}\right) P^{*},
$$

which is strictly equivalent to

$$
\phi^{*}=\left(d+l_{P}\right) P^{*} .
$$

There is thus a linear relationship between plant biomass and plant productivity so that when plant biomass is maximized at a given value of $\beta$, primary productivity is also maximized and reciprocally.

\section{Minimization of Mineral N Losses When Plant Biomass Is Maximized}

From the differential equations describing the $N_{\mathrm{A}}$ (eq. [A3]) and $N_{\mathrm{N}}$ (eq. [A4]) compartments dynamics, at equilibrium state, we have

$$
\begin{aligned}
& l_{N_{\mathrm{A}}} N_{\mathrm{A}}^{*}=m D^{*}+R_{\mathrm{A}}-n N_{\mathrm{A}}^{*}-u \beta P^{*} N_{\mathrm{A}}^{*}, \\
& l_{N_{\mathrm{N}}} N_{\mathrm{N}}^{*}=R_{\mathrm{N}}+n N_{\mathrm{A}}^{*}-u(1-\beta) P^{*} N_{\mathrm{N}}^{*} .
\end{aligned}
$$

We can thus express the sum of the mineral $\mathrm{N}$ losses as

$$
l_{N_{\mathrm{A}}} N_{\mathrm{A}}^{*}+l_{N_{\mathrm{N}}} N_{\mathrm{N}}^{*}=R_{\mathrm{A}}+R_{\mathrm{N}}+m D^{*}-u P^{*}\left[\beta N_{\mathrm{A}}^{*}+(1-\beta) N_{\mathrm{N}}^{*}\right] .
$$

From equation (A1), at equilibrium state, we have

$$
u P^{*}\left[\beta N_{\mathrm{A}}^{*}+(1-\beta) N_{\mathrm{N}}^{*}\right]=\left(d+l_{P}-f\right) P^{*},
$$

so that

$$
l_{N_{\mathrm{A}}} N_{\mathrm{A}}^{*}+l_{N_{\mathrm{N}}} N_{\mathrm{N}}^{*}=R_{\mathrm{A}}+R_{\mathrm{N}}+m D^{*}-\left(d+l_{P}-f\right) P^{*} .
$$

We can then express the variation of the total $\mathrm{N}$ mineral losses with respect to $\beta$ :

$$
\begin{aligned}
& \frac{d\left(l_{N_{\mathrm{A}}} N_{\mathrm{A}}^{*}+l_{N_{\mathrm{N}}} N_{\mathrm{N}}^{*}\right)}{d \beta}=\frac{d\left(m D^{*}\right)}{d \beta}-\frac{d\left[\left(d+l_{P}-f\right) P^{*}\right]}{d \beta}, \\
& \frac{d\left(l_{N_{\mathrm{A}}} N_{\mathrm{A}}^{*}+l_{N_{\mathrm{N}}} N_{\mathrm{N}}^{*}\right)}{d \beta}=\left[\frac{m}{m+l_{D}} d-\left(d+l_{P}-f\right)\right] \frac{d P^{*}}{d \beta} .
\end{aligned}
$$

From this expression we see that $d P^{*} / d \beta=0$ is strictly equivalent to

$$
\frac{d\left(l_{N_{\mathrm{A}}} N_{\mathrm{A}}^{*}+l_{N_{\mathrm{N}}} N_{\mathrm{N}}^{*}\right)}{d \beta}=0,
$$

so that if $P^{*}$ reaches an extremum, the total losses of mineral $\mathrm{N}$ also reach an extremum and vice versa. Since $[\mathrm{m} /(\mathrm{m}+$ $\left.\left.l_{D}\right)\right] d-\left(d+l_{P}-f\right)$ is always negative (see above), we can also say that when $\beta$ varies, $\mathrm{N}$ losses and plant biomass always change in opposite ways.

\section{Reference Cited Only in Appendix A}

Boudsocq, S., S. Barot, and N. Loeuille. 2011. Evolution of nutrient acquisition: when adaptation fills the gap between contrasting ecological theories. Proceedings of the Royal Society B: Biological Sciences 278:449-457. 


\section{Appendix B: Sensitivity of $\boldsymbol{\beta}_{\text {opt }}$ to fluxes and rates of $\mathbf{N}$}

We analyzed the sensitivity of $\beta_{\text {opt }}$ to the rate of nitrification, the rates of nitrogen $(\mathrm{N})$ inputs, and the rate of $\mathrm{N}$ losses for the two ecosystems studied (for Pawnee, see Fig. B-a; for Lamto, see Fig. B-b, at the end of this appendix). We found a negative relationship between $\beta_{\text {opt }}$ and the rate of nitrification for the two ecosystems (panels A in Figs. B-a and B-b). We also observed a non-linear negative relationship between $\beta_{\text {opt }}$ and the rate of $\mathrm{NO}_{3}{ }^{-}$deposition (panels B in Figs. B-a and B-b). As a result, at high nitrification rates or at high $\mathrm{NO}_{3}{ }^{-}$deposition rates, plant biomass and primary productivity are maximized for low $\beta$ values. Both nitrification and $\mathrm{NO}_{3}{ }^{-}$deposition rates increase $\mathrm{NO}_{3}{ }^{-}$availability. Thus, the higher these rates, the higher the $\mathrm{NO}_{3}{ }^{-}$availability, and the higher the plant productivity for plants exhibiting a high preference for $\mathrm{NO}_{3}{ }^{-}$. In contrast, we found a positive non-linear relationship between $\beta_{\text {opt }}$ and the rate of $\mathrm{NH}_{4}{ }^{+}$deposition (panels $\mathrm{C}$ in Figs. B-a and B-b). Consistent to what was expected, atmospheric $\mathrm{NH}_{4}{ }^{+}$deposition increases the availability of $\mathrm{NH}_{4}{ }^{+}$, so that the productivity of plants with high affinities for $\mathrm{NH}_{4}{ }^{+}$increases with $\mathrm{NH}_{4}{ }^{+}$deposition rate.

Finally, except for low rates of $\mathrm{NO}_{3}^{-}$loss (i.e. lower than $0.35 \mathrm{yr}^{-1}$ for the Pawnee site, and lower than $0.5 \mathrm{yr}^{-1}$ for the Lamto site), we also found a positive non-linear relationship between $\beta_{\text {opt }}$ and the rate of $\mathrm{NO}_{3}{ }^{-}$loss (panels D in Figs. B-a and B-b). As losses of $\mathrm{NO}_{3}{ }^{-}$lead to a decrease in its availability for plants, primary productivity is higher for plants preferring $\mathrm{NH}_{4}^{+}$when losses of $\mathrm{NO}_{3}{ }^{-}$ increase. However, for low rates of $\mathrm{NO}_{3}^{-}$loss (i.e. lower than $0.35 \mathrm{yr}^{-1}$ for the Pawnee site, and lower than $0.5 \mathrm{yr}^{-1}$ for the Lamto site), $\beta_{\text {opt }}$ decreases as $\mathrm{NO}_{3}^{-}$loss increases. This pattern might be explained by the fact that an increase in the rate of $\mathrm{NO}_{3}{ }^{-}$loss results in higher losses of mineral $\mathrm{N}$ (i.e. a lower $\mathrm{N}$ recycling efficiency for the ecosystem), that can be counterbalanced by a higher preference for $\mathrm{NO}_{3}{ }^{-}$: increasing the absorption of nitrate decreases $\mathrm{NO}_{3}{ }^{-}$losses. For higher rates of $\mathrm{NO}_{3}{ }^{-}$losses, the ecosystem is so depleted in $\mathrm{NO}_{3}{ }^{-}$that it is no longer worth for the plant to invest in $\mathrm{NO}_{3}{ }^{-}$uptake, so that the optimal affinity for $\mathrm{NH}_{4}{ }^{+}$increases with $\mathrm{NO}_{3}{ }^{-}$losses.

These results show that the rates of nitrification, $\mathrm{N}$ outputs, and atmospheric $\mathrm{N}$ inputs, can strongly affect $\beta_{\text {opt }}$. In turn, this also shows that $\mathrm{N}$ outputs, and atmospheric $\mathrm{N}$ inputs interact with the preference for $\mathrm{NH}_{4}^{+} v s \mathrm{NO}_{3}^{-}$to determine plant biomass and primary production. These results are of particular importance in the context of global environmental changes. Indeed, numerous studies predict a net increase in the deposition rates of $\mathrm{NH}_{4}^{+}$and $\mathrm{NO}_{3}^{-}$(Holland et al., 1999; Galloway et al., 2004; Galloway et al., 2008). While the influence of human activities on N cycle has been already predicted to impact plant communities composition and biodiversity, it has so far never been suggested that this could depend on plant affinity for $\mathrm{NH}_{4}{ }^{+} v s \mathrm{NO}_{3}{ }^{-}$. For example, it is stated that the majority of $\mathrm{N}$ depositions in Europe are in $\mathrm{NH}_{4}{ }^{+}$form, whereas they are in $\mathrm{NO}_{3}{ }^{-}$form in North America (Gilliam, 2006). It could thus be interesting to evaluate the influence of this pattern on plant preference for $\mathrm{NH}_{4}{ }^{+} v S \mathrm{NO}_{3}{ }^{-}$in both continents and on the effect of this preference on plant biomass and primary production in the two continents.

Furthermore, nitrification and $\mathrm{N}$ loss rates are expected to be affected by global changes, and in particular by rising atmospheric $\mathrm{CO}_{2}$ (Barnard et al., 2006; Niboyet et al., 2009). This should affect the relation between plant preference for $\mathrm{NH}_{4}{ }^{+} v s \mathrm{NO}_{3}{ }^{-}$and their biomass and productivity. 
Figure B-a:

A

$\beta_{\text {op }}$

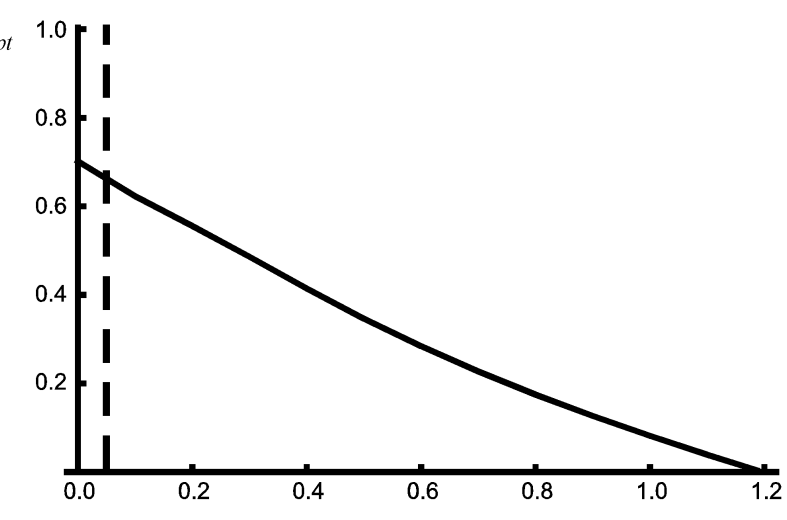

Nitrification rate

C

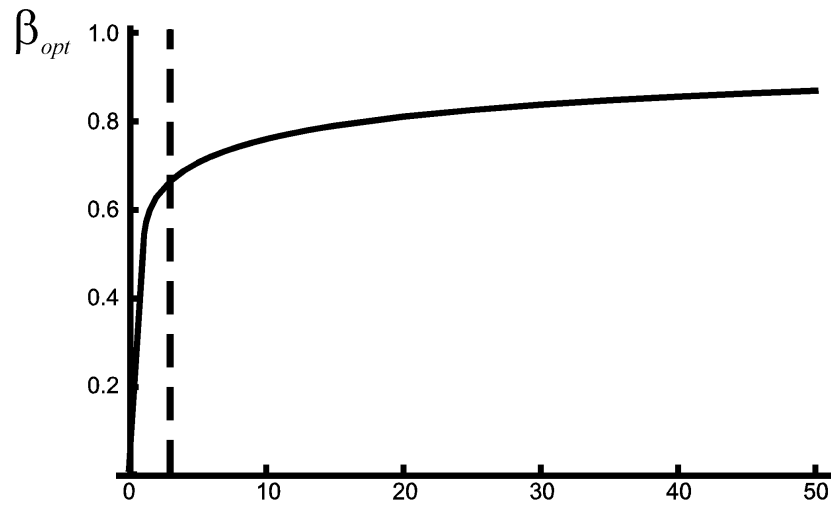

$\mathrm{NH}_{4}^{+}$atmospheric deposition rate
B

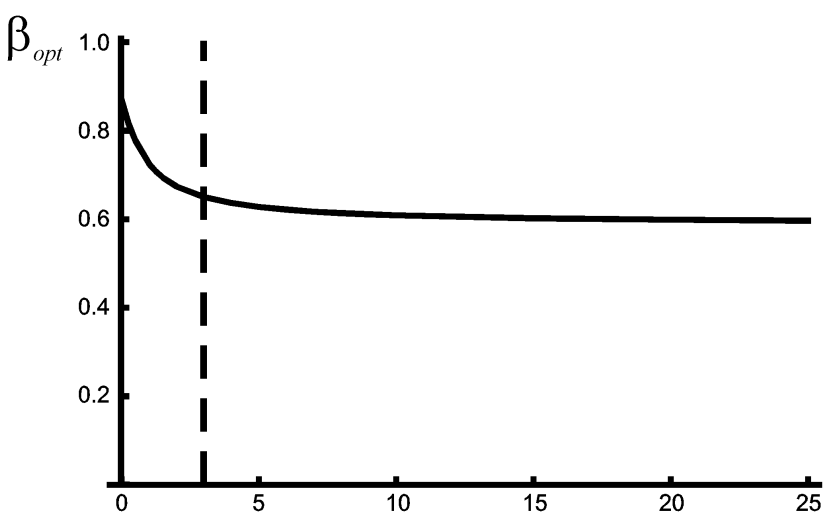

$\mathrm{NO}_{3}^{-}$atmospheric deposition rate
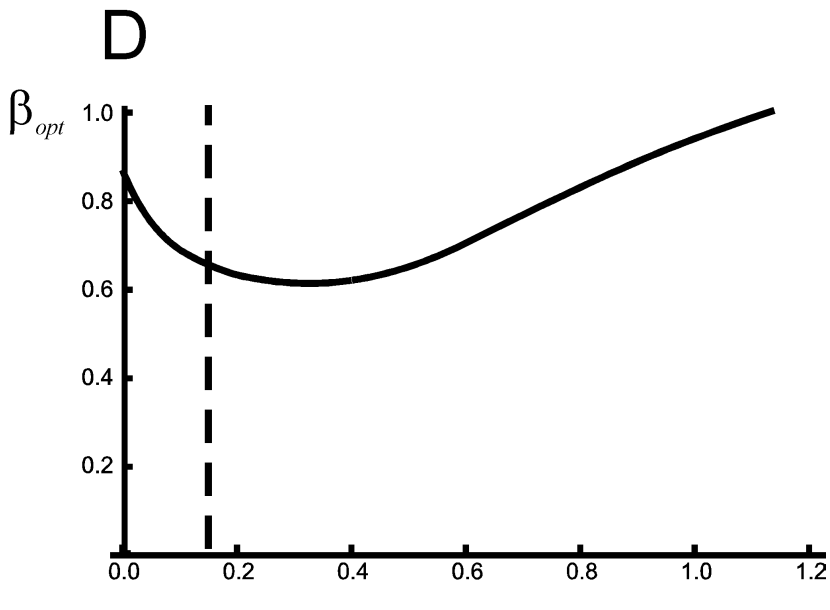

$\mathrm{NO}_{3}^{-}$loss rate

Variations of $\beta_{\text {opt }}$ for the Pawnee site as a function of nitrification (in $\mathrm{yr}^{-1}$ ), $\mathrm{NH}_{4}^{+}$deposition (in $\mathrm{kg} \mathrm{N}$ $\mathrm{ha}^{-1} \mathrm{yr}^{-1}$ ), $\mathrm{NO}_{3}^{-}$deposition (in $\mathrm{kg} \mathrm{N} \mathrm{ha}^{-1} \mathrm{yr}^{-1}$ ) and $\mathrm{NO}_{3}^{-}$loss (in $\mathrm{yr}^{-1}$ ) rates. Dotted lines indicate the values of the corresponding parameters for the Pawnee site (see Table 1 in the main text). 
Figure B-b

A

$\beta_{o p t}$

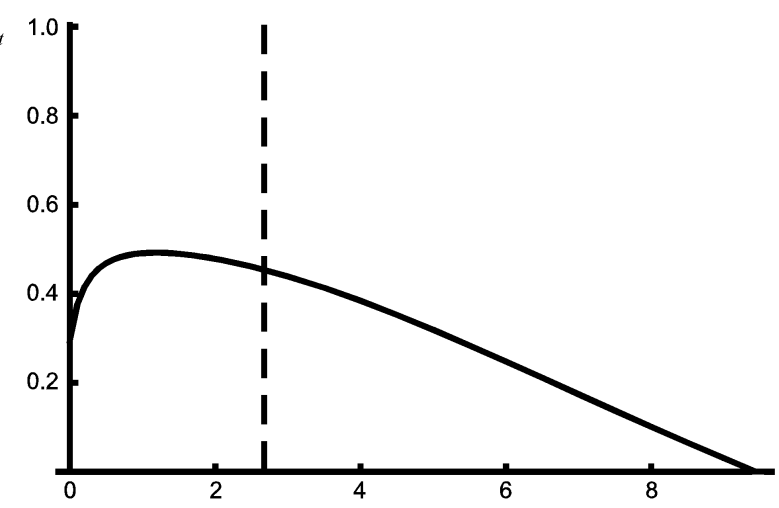

Nitrification rate

C

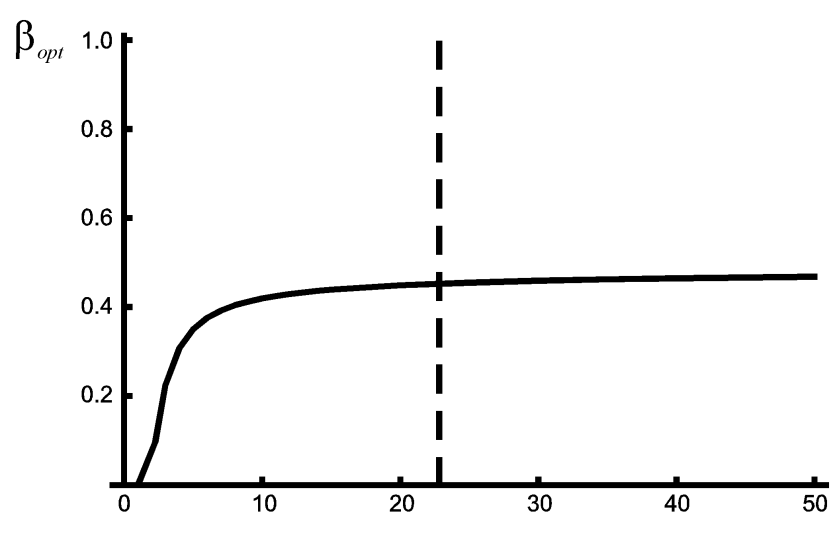

$\mathrm{NH}_{4}^{+}$atmospheric deposition rate
B

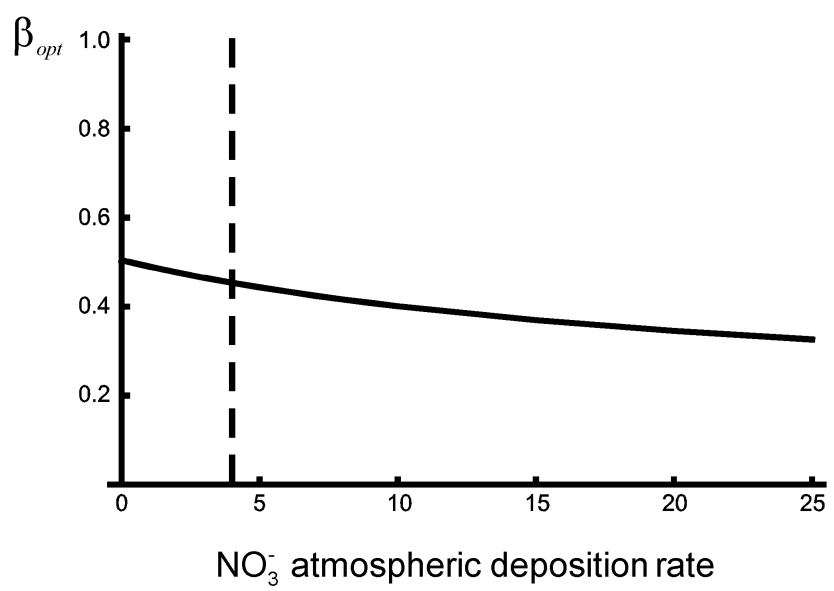

D

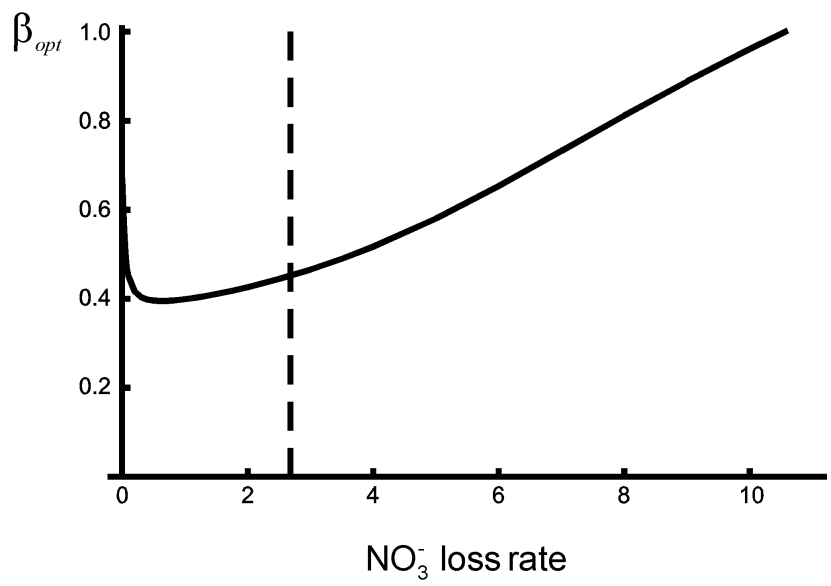

Variations of $\beta_{o p t}$ for the Lamto site as a function of nitrification (in $\mathrm{yr}^{-1}$ ), $\mathrm{NH}_{4}{ }^{+}$deposition (in $\mathrm{kg} \mathrm{N}$ $\mathrm{ha}^{-1} \mathrm{yr}^{-1}$ ), $\mathrm{NO}_{3}^{-}$deposition (in $\mathrm{kg} \mathrm{N}^{-1} \mathrm{yr}^{-1}$ ) and $\mathrm{NO}_{3}^{-}$loss (in $\mathrm{yr}^{-1}$ ) rates. Dotted lines indicate the values of the corresponding parameters for the Lamto site (see Table $\mathrm{C}$ in online appendix $\mathrm{C}$ ). 


\section{Appendix C: Lamto site}

The Lamto savanna $\left(5^{\circ} 02^{\prime} \mathrm{W}, 6^{\circ} 13^{\prime} \mathrm{N} ; 200 \mathrm{~km}\right.$ North of Abidjan, Ivory Coast) has been studied for more than 40 years and is one of the best documented tropical ecosystems in the world (Abbadie \& Lata, 2006). This savanna is subject to large losses of $\mathrm{N}$ caused by annual fires, and has low organic matter decomposition rates, low $\mathrm{N}$ and $\mathrm{C}$ soils, as well as a general lack of nutrients. Paradoxically however, this ecosystem shows one of the highest plant productivity ever observed (Villecourt \& Roose, 1978; Villecourt, Schmidt, \& Cesar, 1979; Bate, 1981). Here, we consider the open shrub savanna which is dominated by the herbaceous Hyparrhenia diplandra and is the most studied type of vegetation in Lamto (Menaut \& Cesar, 1979). Our model has been parametrized for a zone that exhibits a high rate of nitrification (Boudsocq et al., 2009), the site parameters can be found in Table $\mathrm{C}$ of this online appendix.

\section{Ecosystem Properties}

As was the case for the Pawnee site, we found a value of $\beta\left(\beta_{\text {opt }}\right)$ that maximizes plant biomass and primary productivity, and minimizes mineral $\mathrm{N}$ losses (Fig. $\mathrm{C}-\mathrm{a}$, see at the end of this Appendix $)$. Again, the value of $\beta_{\text {opt }}(\approx 0.45)$ also corresponds to a generalist strategy, and for extreme values of $\beta$ ( 0 and 1$)$, plant biomass and primary productivity are the lowest. Concerning the mineral $\mathrm{N}$ stocks and their associated losses, the higher the affinity for $\mathrm{NH}_{4}{ }^{+}$, the lower the size of the $\mathrm{NH}_{4}{ }^{+}$pool, while $\mathrm{NO}_{3}{ }^{-}$stock is maximized for extreme values of $\beta$ and minimized for an intermediate value of $\beta$. As a consequence, and as for the Pawnee site (see main text), total mineral $\mathrm{N}$ losses are minimized for an intermediate value of $\beta$, and are maximized for extreme values of $\beta$. Finally, the only qualitative difference with the Pawnee site is the continuous decrease in $\mathrm{NH}_{4}^{+}$ availability as $\beta$ increases (i.e. with no increase for very low values of $\beta$, Fig. 2 of the main text). We hypothesize that this is due to the fact that, in Lamto savanna, the losses of $\mathrm{NH}_{4}^{+}$are low relative to the total losses the ecosystem is subject to (which is not the case in Pawnee). In particular, $\mathrm{NH}_{4}^{+}$losses are lower in Lamto than in Pawnee. We hypothesized (see in the main text) that in Pawnee, increasing $\beta$ starting from low $\beta$ values increases the global recycling efficiency, which compensates for the increasing consumption of $\mathrm{NH}_{4}{ }^{+}$and subsequently leads to an increase in $\mathrm{NH}_{4}^{+}$availability. In Lamto, losses of $\mathrm{NH}_{4}^{+}$being low, increasing the absorption of $\mathrm{NH}_{4}^{+}$is not likely to increase significantly the general recycling efficiency of the ecosystem. A sensitivity study (not displayed here) supports this rationale.

\section{Coexistence and invasions}

Concerning the patterns of invasion and coexistence, the main difference between the Lamto and the Pawnee sites is the width of each zone for the nitrification stimulation case. Indeed, for Lamto savanna, in the case where $P_{2}$ stimulates nitrification, the sum of the coexistence zones and the zone where no invasion is possible are larger than for Pawnee (Fig. C-b, panel B, zones $a / a^{\prime}$ and $d$ ), and the sum of the invasion/exclusion zones is smaller than for Pawnee (Fig. C-b, panel B, zones $c / c^{\prime}$ ). We suggest that the differences between the two sites are due to the higher nitrification rate in Lamto, which leads to a higher sensitivity of the model to inhibition and stimulation of nitrification compared to the Pawnee site. 
Figure C-a

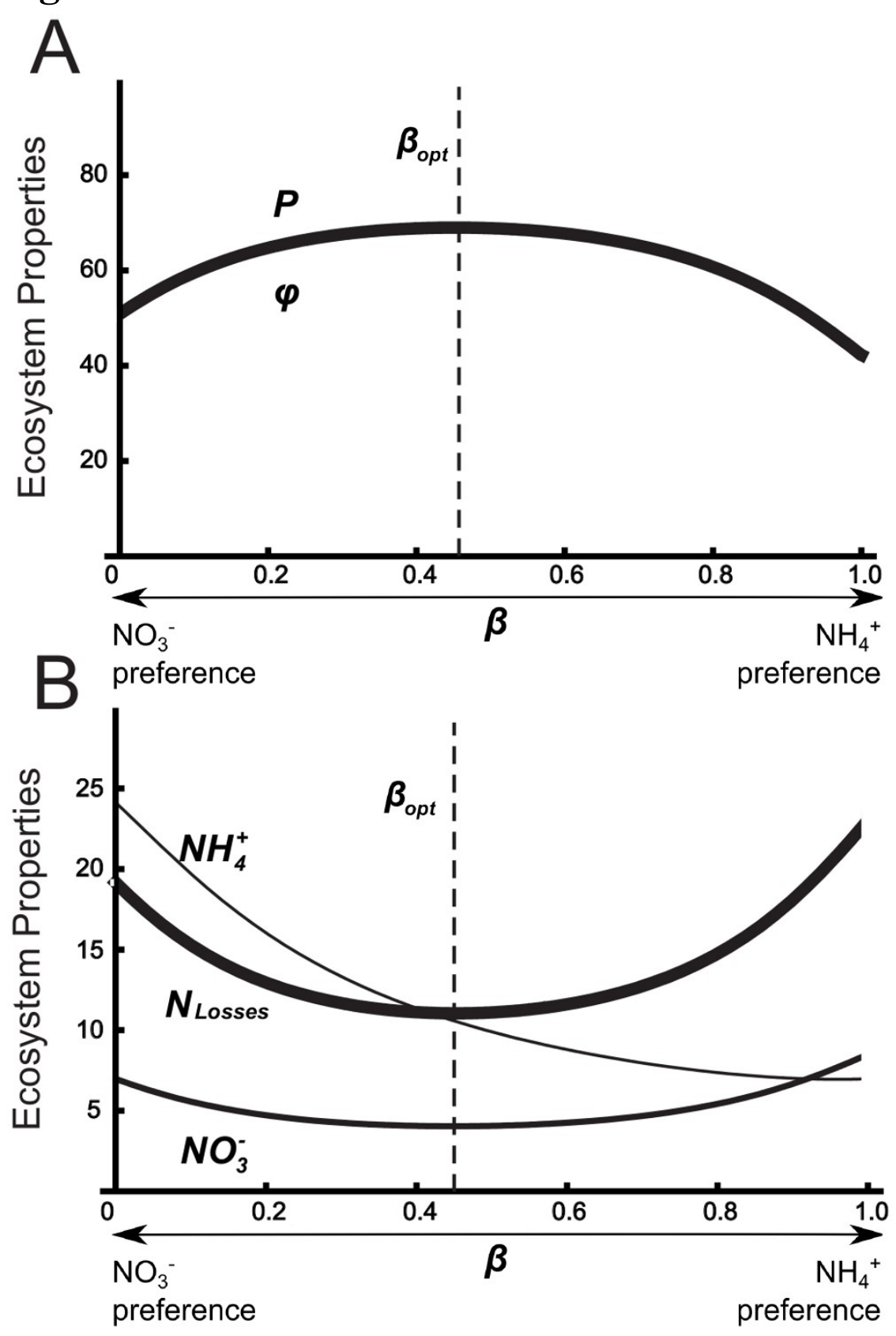

Variations in the size of ecosystem compartments ( $\mathrm{P}$ (panel A), $\mathrm{NH}_{4}^{+}$and $\mathrm{NO}_{3}{ }^{-}$(panel B)) and fluxes (primary productivity $(\varphi)$ (panel A), and $N_{\text {losses }}$ (panel B)) as a function of plant affinity for $\mathrm{NH}_{4}{ }^{+} v s$ $\mathrm{NO}_{3}^{-}(\beta)$ for the Pawnee site. The sizes of the ecosystem compartments are expressed in $\mathrm{kg} \mathrm{N} \mathrm{ha-1}$, and the fluxes are expressed in $\mathrm{kg}$ nutrient $\mathrm{ha}^{-1} \mathrm{yr}^{-1}$. As shown in the figure, $\beta_{\text {opt }}$ corresponds to the maximal plant biomass and primary productivity, and to the minimum of $\mathrm{N}$ losses. Note that plant biomass curve merges with the primary productivity curve, simply because of Lamto site parameters' values. 


\section{Figure C-b}
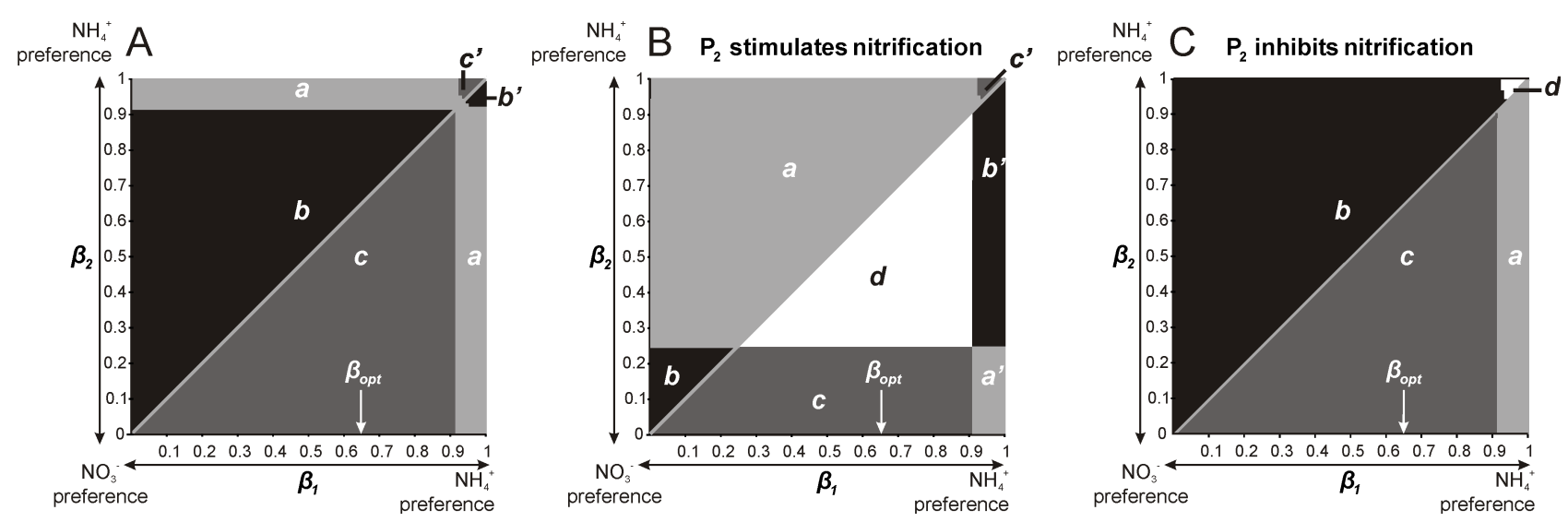

Patterns of invasion and coexistence between two plant species $\left(P_{1}\right.$ and $\left.P_{2}\right)$ for the Lamto site (Panel A: $P_{1}$ and $P_{2}$ only differ in their affinity for ammonium $v s$ nitrate; Panel B: $P_{2}$ stimulates nitrification; Panel C: $P_{2}$ inhibits nitrification). $\beta_{1}$ and $\beta_{2}$ are the $\mathrm{NH}_{4}{ }^{+}$affinities for $P_{1}$ and $P_{2}$ respectively. Distinct zones are indicated: in light grey (a): coexistence; in black (b): $P_{2}$ wins the competition; in dark grey (c): $P_{1}$ wins the competition; in white (d): no invasion and maintaining of residents.

\section{Table C: Parameters of the Lamto site}

From Boudsocq et al. (2009)

\begin{tabular}{|c|c|c|c|}
\hline Parameter & Dimension & Definition & Value \\
\hline$f$ & $\mathrm{yr}^{-1}$ & Symbiotic $\mathrm{N}$ fixation rate & 0.01 \\
\hline$d$ & $\mathrm{yr}^{-1}$ & Plant recycling rate & 0.6 \\
\hline$l_{P}$ & $\mathrm{yr}^{-1}$ & Plant loss rate & 0.4 \\
\hline$R_{D}$ & $\mathrm{~kg} \mathrm{~N} \mathrm{ha}^{-1} \mathrm{yr}^{-1}$ & Annual organic $\mathrm{N}$ input rate & 16.5 \\
\hline$m$ & $\mathrm{yr}^{-1}$ & DOM recycling rate & 0.025 \\
\hline$l_{D}$ & $\mathrm{yr}^{-1}$ & DOM loss rate & 0.0027 \\
\hline$R_{A}$ & $\mathrm{~kg} \mathrm{~N} \mathrm{ha}^{-1} \mathrm{yr}^{-1}$ & Annual $\mathrm{NH}_{4}{ }^{+}$input & 23 \\
\hline$u$ & ha $\mathrm{kg} \mathrm{N}^{-1} \mathrm{yr}^{-1}$ & $\mathrm{~N}$ uptake rate & 0.14186 \\
\hline$n$ & $\mathrm{yr}^{-1}$ & Nitrification rate & 2.7 \\
\hline$l_{N A}$ & $\mathrm{yr}^{-1}$ & $\mathrm{NH}_{4}^{+}$loss rate & 0.0133 \\
\hline$R_{N}$ & $\mathrm{~kg} \mathrm{~N} \mathrm{ha-1} \mathrm{yr}^{-1}$ & Annual $\mathrm{NO}_{3}{ }^{-}$input & 4.1 \\
\hline$l_{N N}$ & $\mathrm{yr}^{-1}$ & $\mathrm{NO}_{3}^{-}$loss rate & 2.7 \\
\hline$\beta$ & dimensionless & Affinity for $\mathrm{NH}_{4}^{+} v s \mathrm{NO}_{3}^{-}$ & NA \\
\hline$i$ & ha $\mathrm{kg} \mathrm{N}^{-1}$ & Nitrification inhibition/stimulation rate & \pm 0.02 \\
\hline
\end{tabular}




\section{Appendix D: Invasion, coexistence and primary productivity}

In this section, we investigate the links between the coexistence/invasion patterns, and the plant primary productivity for the Pawnee site. Two situations are simulated: (1) $P_{1}$ invades $P_{2}$ and (2) $P_{2}$ invades $P_{l}$. The invader has a starting biomass of $0.01 \mathrm{~kg} \mathrm{~N} \mathrm{ha}^{-1}$ while the resident has a starting biomass of $100 \mathrm{~kg} \mathrm{~N} \mathrm{ha}^{-1}$. Three sub-cases are studied: (1) $P_{1}$ and $P_{2}$ only differ by their affinity for $\mathrm{NH}_{4}^{+}$vs $\mathrm{NO}_{3}^{-}$, (2) $P_{2}$ stimulates nitrification, (3) $P_{2}$ inhibits nitrification. There are thus six distinct simulations (Fig. D, at the end of this appendix).

Note that the coexistence/invasion patterns (Fig. 3 in the main text and Fig. C-b of the online appendix C) are combinations of the same type of simulations (displaying biomasses instead of primary productivity). We evaluate here the total primary productivity of $P_{1}$ and $P_{2}$ when both plants coexist. Using a color gradient for the total plant productivity, and by comparing with the first diagram of each panel, we can see that when both plants coexist, the total primary productivity obtained is relatively constant and has an intermediate value (around $15 \mathrm{~kg} \mathrm{~N} \mathrm{ha}^{-1} \mathrm{y}^{-1}$ ). This means that total plant productivity is not optimized by coexistence. Moreover, we observe that when there is no coexistence but competitive exclusion (all zones excepted those corresponding to coexistence), the primary productivity of the remaining plant varies in function of its affinity for $\mathrm{NH}_{4}^{+}$vs $\mathrm{NO}_{3}{ }^{-}$exactly as shown in Fig. 2 of the main text, with a value of this affinity that optimizes plant productivity. This section supports the idea that evolution or species replacement does not necessarily optimize ecosystem properties such as plant biomass or primary productivity (Odum 1969; Loreau 1998; Boudsocq et al. 2011). 


\section{Figure D}

A
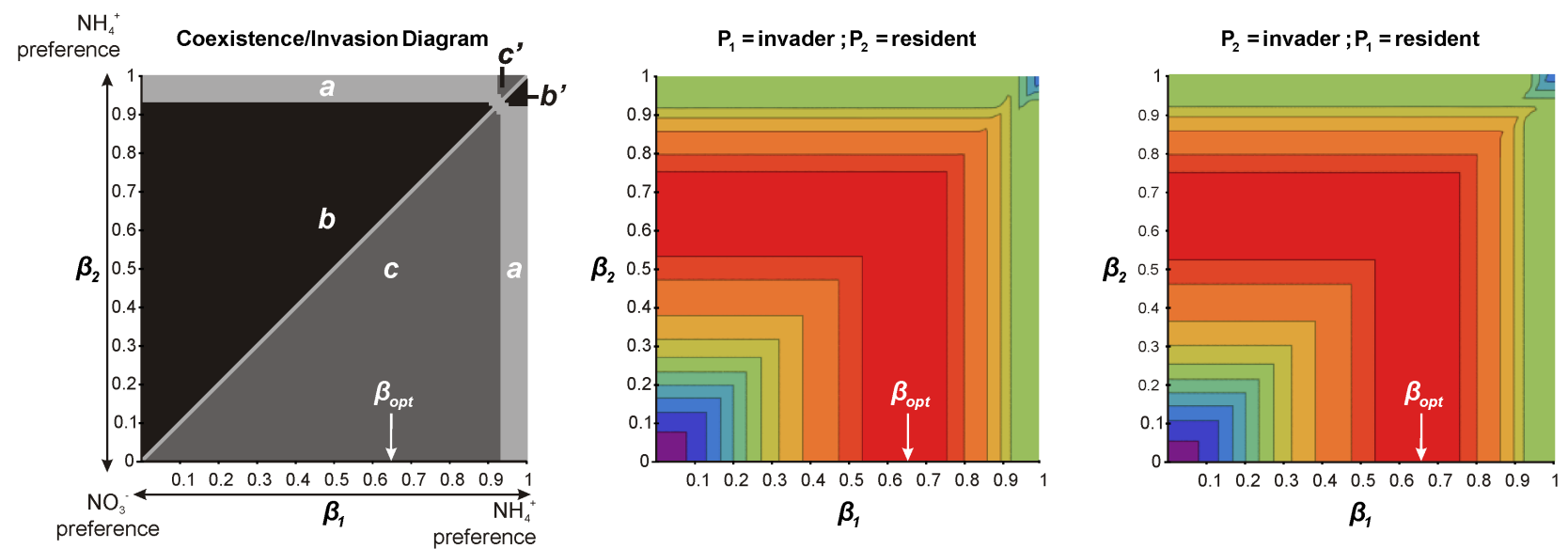

\section{B $P_{2}$ stimulates nitrification}
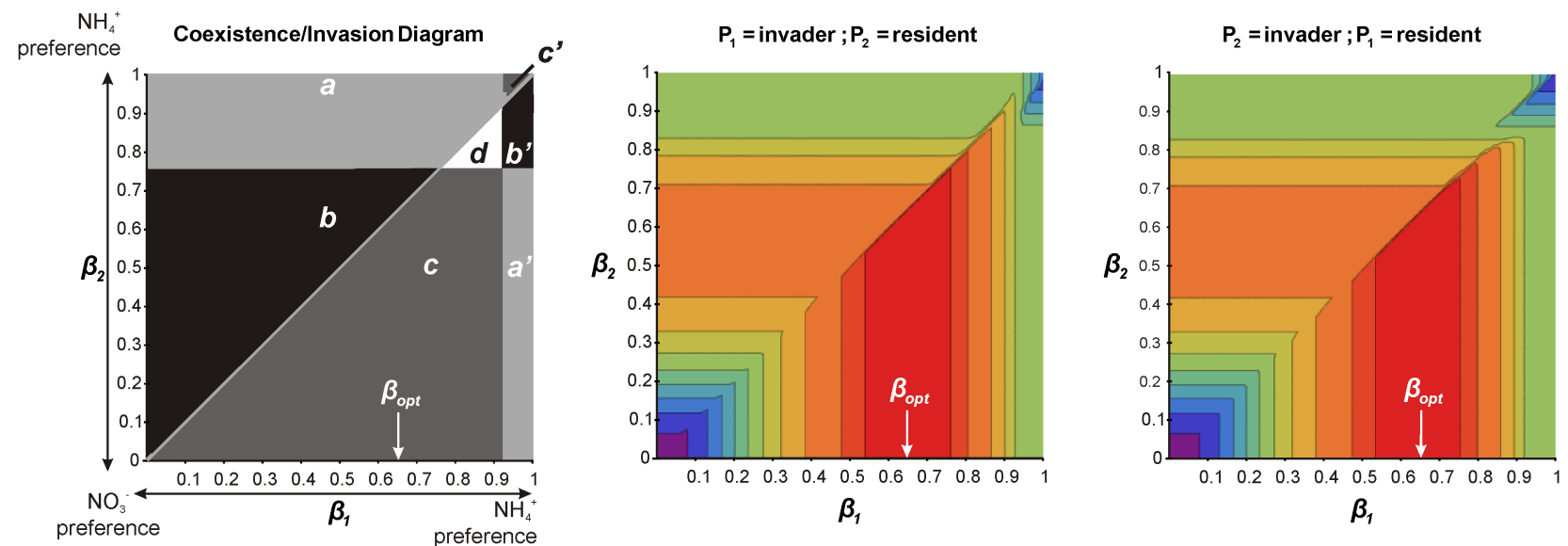

\section{C $P_{2}$ inhibits nitrification}
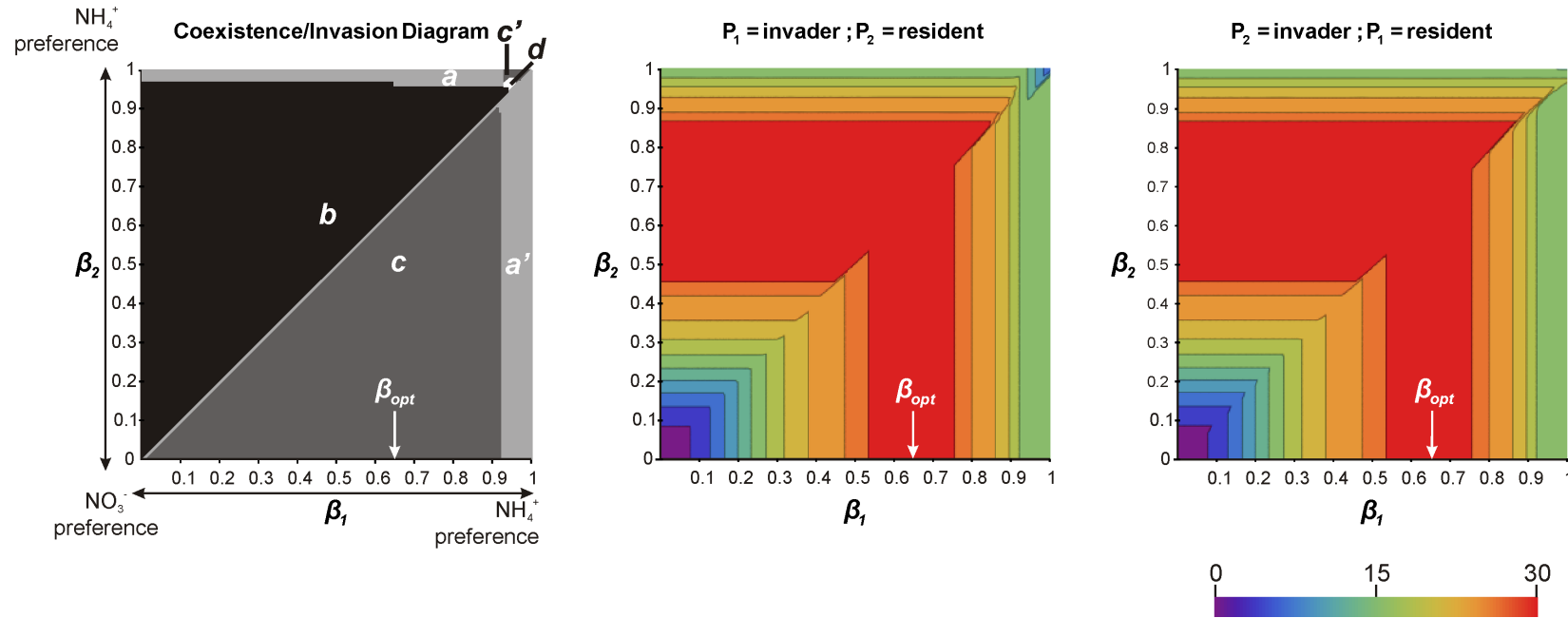

Patterns of invasion and coexistence between two plant species $\left(P_{1}\right.$ and $\left.P_{2}\right)$ for the Pawnee site, and the corresponding plants total primary productivities (Panel A: $P_{1}$ and $P_{2}$ only differ in their affinity for ammonium $v s$ nitrate; Panel B: $P_{2}$ stimulates nitrification; Panel C: $P_{2}$ inhibits nitrification). $\beta_{1}$ and $\beta_{2}$ are the $\mathrm{NH}_{4}{ }^{+}$affinities for $P_{1}$ and $P_{2}$ respectively. Distinct zones are indicated: in light grey (a): coexistence; in black (b): $P_{2}$ wins the competition; in dark grey (c): $P_{1}$ wins the competition; in 
white (d): no invasion and maintaining of residents. For each panel, the left-side diagram is taken from Fig. 3 in the main text and helps to see the different coexistence/invasion patterns. The middle diagram is obtained when $P_{1}$ invades $P_{2}$ and the right-side diagram is obtained when $P_{2}$ invades $P_{1}$. The color gradient indicates the primary productivity value in $\mathrm{kg} \mathrm{N} \mathrm{ha}^{-1} \mathrm{y}^{-1}$.

\section{References}

Abbadie, L. 2006. Nitrogen inputs to and outputs from the soil-plant system. In: Lamto - Structure, functioning, and dynamics of a savanna ecosystem. (eds. L Abbadie, J. Gignoux, X. Roux, and M. Lepage). Springer, New York, NY., pp. 255-275.

Barnard, R., X. Le Roux, B. A. Hungate, E. E. Cleland, J. Blankinship, L. Barthes, L., and P. W. Leadley. 2006. Several components of global change alter nitrifying and denitrifying activities in an annual grassland. Functional Ecology 20:557-564.

Bate, G.C. (1981). Nitrogen Cycling in Savanna Ecosystems. Ecological Bulletins, 33, 463-475.

Boudsocq, S., J.-C. Lata, J. Mathieu, L. Abbadie, and S. Barot. 2009. Modelling approach to analyse the effects of nitrification inhibition on primary production. Functional Ecology 23:220-230.

Boudsocq, S., S. Barot, and N. Loeuille. 2011. Evolution of nutrient acquisition: when adaptation fills the gap between contrasting ecological theories. Proceedings of the Royal Society B: Biological Sciences 278:449-457.

Galloway, J. N., F. J. Dentener, D. G. Capone, E. W. Boyer, R. W. Howarth, S. P. Seitzinger, G. P. Asner, C. C. Cleveland, P. A. Green, E. A. Holland, D. M. Karl, A. F. Michaels, J. H. Porter, A. R. Townsend, and C. J. Vorosmarty. 2004. Nitrogen Cycles: Past, Present, and Future. Biogeochemistry 70:153-226.

Galloway, J. N., A. R. Townsend, J. W. Erisman, M. Bekunda, Z. Cai, J. R. Freney, L. A. Martinelli, S. P. Seitzinger, and M. A. Sutton. 2008. Transformation of the nitrogen cycle: recent trends, questions, and potential solutions. Science. 320:889-892.

Gilliam, F. S. 2006. Response of the herbaceous layer of forest ecosystems to excess nitrogen deposition. Journal of Ecology. 94:1176-1191.

Holland, E. A., F. J. Dentener, B. H. Braswell, and J. M. Sulzman. 1999. Contemporary and preindustrial global reactive nitrogen budgets. Biogeochemistry. 46:7-43.

Loreau, M. 1998. Ecosystem development explained by competition within and between material cycles. Proceedings of the Royal Society B: Biological Sciences 265:33-38.

Menaut, J.-C., and J. Cesar. 1979. Structure and primary productivity of Lamto savannas, Ivory Coast. Ecology 60:1197-1210.

Niboyet, A., L. Barthes, B. A. Hungate, X. Le Roux, J. M. G. Bloor, A. Ambroise. S. Fontaine, P. M. Price, and P. W. Leadley. 2009. Responses of soil nitrogen cycling to the interactive effects of elevated $\mathrm{CO}_{2}$ and inorganic N supply. Plant and Soil 327:35-47.

Odum, E. P. 1969. The Strategy of Ecosystem Development. Science 164:262-270.

Villecourt, P., and E. Roose. 1978. Charge en azote et en éléments minéraux majeurs des eaux de pluie, de pluviolessivage et de drainage dans la savane de Lamto (Côte d'Ivoire). Revue d'Ecologie et de Biologie du Sol 15:1-20.

Villecourt, P., W. Schmidt, and J. Cesar. 1979. Recherche sur la composition chimique (N, P, K) de la strate herbacée de la savane de Lamto (Côte d'Ivoire). Revue d'Ecologie et de Biologie du Sol 16:9-15. 